\title{
The gating pore blocker 1-(2,4-xylyl)guanidinium selectively inhibits pacemaking of midbrain dopaminergic neurons
}

\author{
Kevin Jehasse ${ }^{\mathrm{a}}$, Laurent Massotte ${ }^{\mathrm{a}}$, Sebastian Hartmann ${ }^{\mathrm{b}}$, Romain Vitello ${ }^{\mathrm{c}}$, Sofian Ringlet ${ }^{\mathrm{a}}$, \\ Marie Vitello $^{\text {a, }}$, Han Chow Chua ${ }^{\mathrm{d}}$, Stephan A. Pless ${ }^{\mathrm{d}}$, Dominique Engel ${ }^{\mathrm{a}}$, \\ Jean-François Liégeois ${ }^{c}$, Bernard Lakaye ${ }^{\mathrm{e}}$, Jochen Roeper ${ }^{\mathrm{b}, 1}$, Vincent Seutin ${ }^{\mathrm{a}, 1, *}$

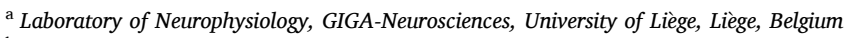 \\ ${ }^{\mathrm{b}}$ Institute for Neurophysiology, Goethe University, Frankfurt, Germany \\ ${ }^{\mathrm{c}}$ Laboratory of Medicinal Chemistry, CIRM, University of Liège, Liège, Belgium \\ ${ }^{\mathrm{d}}$ Department of Drug Design and Pharmacology, University of Copenhagen, Denmark \\ ${ }^{\mathrm{e}}$ Laboratory of Molecular Regulation of Neurogenesis, GIGA-Stem Cells, University of Liège, Liège, Belgium
}

\section{A R T I C L E I N F O}

\section{Keywords:}

Dopaminergic neuron

Slow pacemaker

Patch clamp

Pacemaker clamp

\begin{abstract}
A B S T R A C T
Although several ionic mechanisms are known to control rate and regularity of the slow pacemaker in dopamine (DA) neurons, the core mechanism of pacing is controversial. Here we tested the hypothesis that pacemaking of SNc DA neurons is enabled by an unconventional conductance. We found that 1-(2,4-xylyl)guanidinium (XG), an established blocker of gating pore currents, selectively inhibits pacemaking of DA neurons. The compound inhibited all slow pacemaking DA neurons that were tested, both in the substantia nigra pars compacta, and in the ventral tegmental area. Interestingly, bursting behavior was not affected by XG. Furthermore, the drug did not affect fast pacemaking of GABAergic neurons from substantia nigra pars reticulata neurons or slow pacemaking of noradrenergic neurons. In DA neurons, current-clamp analysis revealed that XG did not appear to affect ion channels involved in the action potential. Its inhibitory effect persisted during blockade of all ion channels previously suggested to contribute to pacemaking. RNA sequencing and voltage-clamp recordings yielded no evidence for a gating pore current to underlie the conductance. However, we could isolate a small subthreshold XG-sensitive current, which was carried by both $\mathrm{Na}^{+}$and $\mathrm{Cl}^{-}$ions. Although the molecular target of XG remains to be defined, these observations represent a step towards understanding pacemaking in DA neurons.
\end{abstract}

\section{Introduction}

Midbrain dopamine (DA) neurons are slow pacemaker neurons. They are involved in diverse psychomotor functions including control of movement, reward, motivation and cognition (Nieoullon, 2002; Schultz, 2007; Wise, 2004). Although several subpopulations of midbrain DA neurons have been described based on their projections, transcriptomic profiles and electrophysiological properties (Evans et al., 2017; Farassat et al., 2019; Liss and Roeper, 2008; Margolis et al., 2008; Neuhoff et al., 2002; Philippart et al., 2016; Poulin et al., 2014), the majority of DA neurons are able to fire action potentials (AP) spontaneously at low frequency, in the range of $1-5 \mathrm{~Hz}$, which might ensure a basal level of DA signaling in the target areas (Albin et al., 1989; Gonon and Bloch, 1998; Grace and Bunney, 1984). This is true both in the substantia nigra pars compacta (SNc) and in the ventral tegmental area (VTA). These neurons are also known to switch their firing mode from pacemaking to burst activity in response to synaptic input (Grace and Bunney, 1984).

While the onset of bursting is clearly linked to activation of NMDA receptors (Blythe et al., 2007; Destreel et al., 2019; Galtieri et al., 2017; Johnson et al., 1992), the exact mechanism that enables slow pacemaking in DA neurons is still unknown. Blocking the hyperpolarization-activated cation channels $(\mathrm{HCN})$ that sustain $\mathrm{I}_{\mathrm{h}}$ does not stop the autonomous activity of DA neurons, but slows the firing frequency of some of them (Neuhoff et al., 2002; Seutin et al., 2001). It was also suggested that L-type voltage-gated calcium $\left(\mathrm{Ca}_{\mathrm{v}}\right)$ channels drive the spontaneous firing, as applying dihydropyridines (DHPs) slows or even silences the pacemaking of DA SNc neurons (Chan et al., 2007; Mercuri et al., 1994; Nedergaard et al., 1993; Puopolo et al., 2007).

\footnotetext{
* Corresponding author. Laboratory of Neurophysiology, GIGA-Neurosciences, University of Liège, Avenue Hippocrate 15, B-4000 Liège, Belgium.

E-mail address: V.Seutin@uliege.be (V. Seutin).

1 Both last authors contributed equally to this work.
} 
However, these experiments were made using high concentration of DHPs, possibly leading to off-target actions or these effects were observed only in a subset of the recorded cells (Puopolo et al., 2007). Another study found no effect of lower concentrations of DHPs on the pacemaker frequency (Guzman et al., 2009).

Understanding what happens during the interspike interval (ISI) is key to uncover the nature of the autonomous activity of DA neurons. The coefficient of variation of the interspike interval (ISI) in DA SNc neurons ex vivo is very low, in the range of 5\% (de Vrind et al., 2016). The current amplitude needed to depolarize DA neurons during the ISI has been estimated to be around 5 pA (Khaliq and Bean, 2008). Taking into account the gating properties and the single channel conductance of most voltage-gated ion channels, which lies around $20 \mathrm{pS}$, this would mean that few ion channels would underlie this current. Given the stochastic
A<smiles>Cc1ccc(NC(=N)N)c(C)c1</smiles>

1-(2,4-Xyly) Guanidine
B

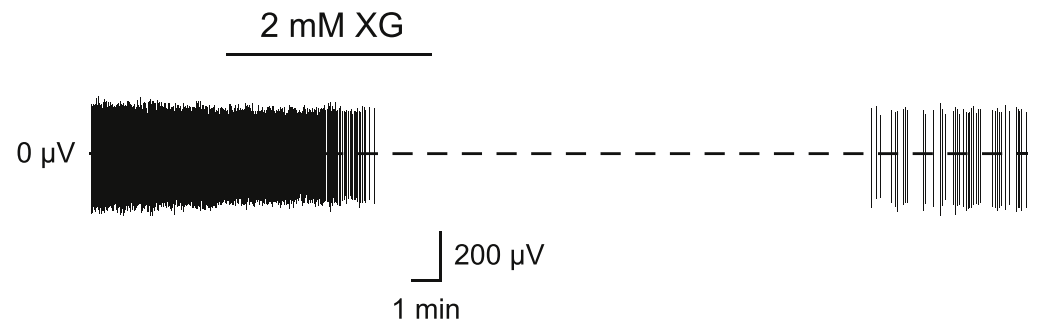

C

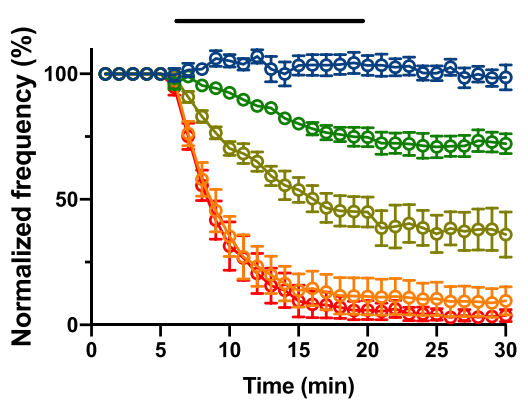

$E$

\section{Control}

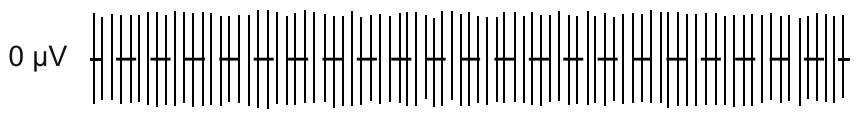

$2 \mathrm{mM} X \mathrm{G}$

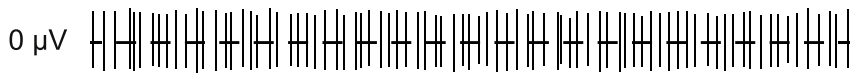

$400 \mathrm{mV}$ $\rightarrow$ Control

$\diamond 0.2 \mathrm{mM} X \mathrm{G}$

$\odot 0.6 \mathrm{mM} X \mathrm{G}$

- $2 \mathrm{mMXG}$

- $6 \mathrm{mMXG}$
D

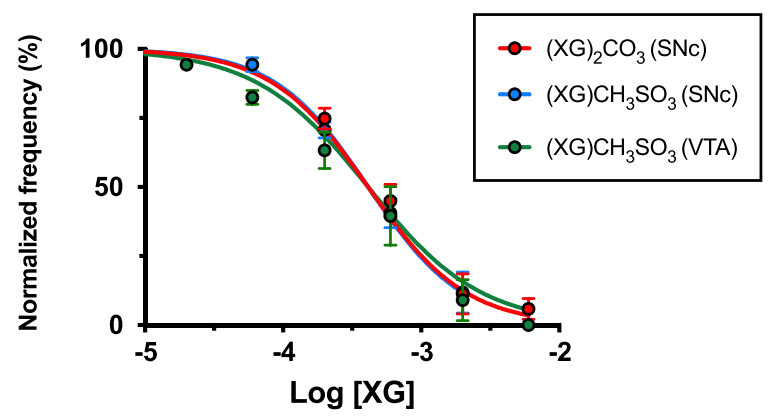

F

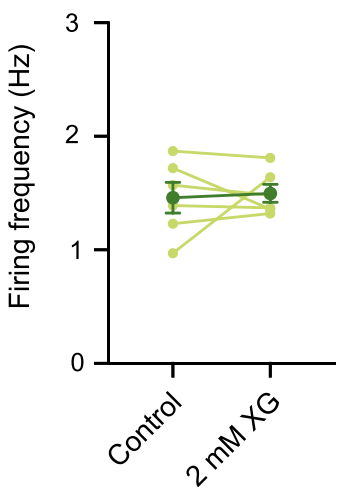

$5 \mathrm{~s}$

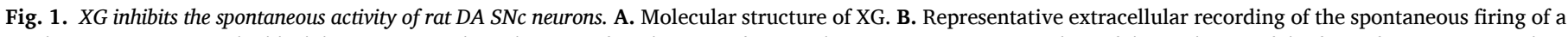

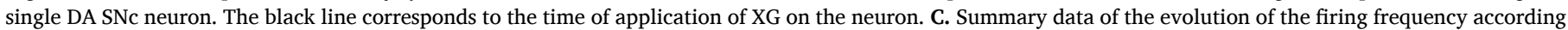

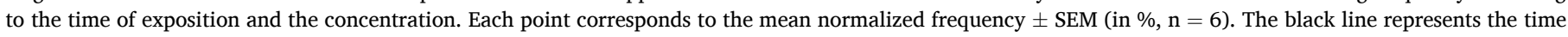

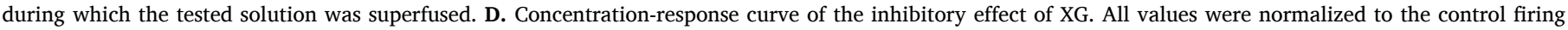

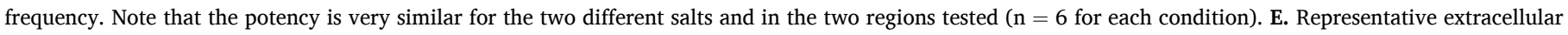

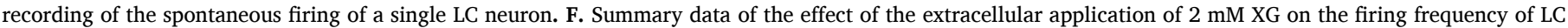

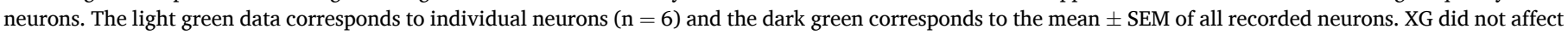

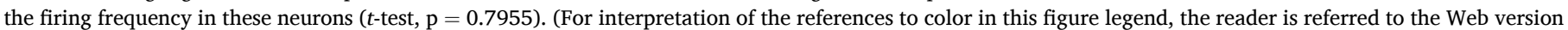
of this article.) 
nature of ion channel opening, such a current would inevitably be very noisy, which is incompatible with the small coefficient of variation of the ISI of DA neurons. A second option would be the result from the almost perfect cancellation of inward and outward currents ensuring the robustness of pacemaking (O'Leary et al., 2014). In DA neurons, this could be mediated by fast-activating $\mathrm{K}_{\mathrm{v}} 4$ (sustaining $I_{A}$ ) channels cooperating with HCN channels, but blocking both channels does not stop the pacemaking and only affects rebound firing after a hyperpolarizing current injection (Amendola et al., 2012).

A third possibility would be the recruitment of many small conductance pores to ensure a steady pacemaking. We therefore turned our attention to unconventional pores displaying a very low conductance, in the range of fS, such as currents generated from gating pores ("gating pore currents" or "omega currents" $\left.\left(I_{\omega}\right)\right)$. $I_{\omega}$ is generally the result of a pathological mutation in the voltage sensor domain, creating a pore through which ions can flow (Jiang et al., 2018; Sokolov et al., 2007; Tombola et al., 2005). Their conductance has been estimated to be $1-6 \%$ of the conductance of the main $\alpha$ pore of voltage-gated channels (Held et al., 2016). It was subsequently found that $I_{\omega}$ generated from a mutant voltage-gated sodium $\left(\mathrm{Na}_{\mathrm{V}}\right)$ channel is selectively blocked by 1-(2, 4-xylyl)guanidinium (XG) (Fig. 1A) (Sokolov et al., 2010). Since XG does not interact with the $\alpha$ pore of $\mathrm{Na}_{\mathrm{v}}$ channel, we used it as a pharmacological tool to probe for the possible existence of $I_{\omega}$ currents in DA SNc neurons. We found that XG does inhibit the pacemaking of DA neurons, probably by acting on a "gating-pore-like" target that carries both $\mathrm{Na}^{+}$ and $\mathrm{Cl}^{-}$ions.

\section{Materials and methods}

\subsection{Animals}

All our experiments were performed in accordance with the ethical guidelines of the European Union (Directive, 2010/63/EU). In addition, all procedures of animal care, handling and sacrifice were approved by the Ethics Committee for Animal Use of Liège University (protocol 1210)

Both juvenile (18-26 days) and adult (6-8 weeks) Wistar rats of either sex were used for patch-clamp and extracellular recordings, respectively. DA neurons reach their electrophysiological maturity at P18 (Dufour et al., 2014; Tepper et al., 1994). Juvenile C57BL/6 N mice were used as well for both types of recordings. A mouse model bearing a complete KO for the DAT was also used in extracellular recordings. This mouse line (Giros et al., 1996) was kindly provided by Pr. Marc Caron (Duke University, Durham, NC, USA) and has been amply characterized.

\subsection{Molecular biology}

Parts of the SNc and cortex were isolated from adult rat brains and kept at $-80{ }^{\circ} \mathrm{C}$. RNA was extracted using the "Monarch Total RNA Miniprep" kit (New England Biolabs, Ipswich, MA, USA) and then was reverse transcribed by random priming using the PrimeScript RT Reagent Kit (Takara Bio Europe, Saint-Germain-en-Laye, France). PCRs were performed using the Q5 polymerase (New England Biolabs) and specific primer pairs (Integrated DNA Technologies, Leuven, Belgium). Specificity of amplification was first assessed by gel agarose analysis and then PCR fragments were processed by the GIGA-Genomics platform (GIGA Institute, Liège University) for high throughput sequencing on an Illumina sequencer.

The sequences of primer pairs that were designed to amplify the fourth alpha-helices of each transmembrane domain of the voltagegated $\mathrm{Na}^{+}$channels and of the HCN channels, or to amplify the IQ domain of the voltage-gated $\mathrm{Ca}^{2+}$ channel, are given in Table S1. Delineations of alpha-helices or of the IQ domain are given under the accession number describing each channel.

\subsection{Electrophysiology}

Animals were anaesthetized with isoflurane and sacrificed by decapitation. The brain was quickly removed and submerged in an oxygenated ice-cold physiological saline solution (ACSF) containing the following (in mM): $125 \mathrm{NaCl}, 2.5 \mathrm{KCl}, 1 \mathrm{MgCl}_{2}, 2 \mathrm{CaCl}_{2}, 10$ (extracellular recordings) or 25 (patch clamp recordings) glucose, $1.25 \mathrm{NaH}_{2} \mathrm{PO}_{4}$, $25 \mathrm{NaHCO}_{3}$, pH $7.4\left(95 \% \mathrm{O}_{2} 5 \% \mathrm{CO}_{2}\right.$ and $\left.310 \mathrm{mosm} / \mathrm{L}\right)$. Coronal or horizontal $300 \mu \mathrm{M}$-thick slices were obtained using a vibratome (Leica VT-1200, Nussloch, Germany) for patch-clamp and extracellular recordings respectively. Midbrain slices were incubated at $34^{\circ} \mathrm{C}$ for $30-60$ min before being stored at room temperature.

Extracellular recordings were performed as previously described (Drion et al., 2011). DA neurons were identified based on their low firing rate $(0.5-5 \mathrm{~Hz})$, long AP duration $(>2 \mathrm{~ms}$ ) and very regular pacemaking activity $\left(\mathrm{CV}_{\mathrm{ISI}}<10 \%\right.$ over a $5 \mathrm{~min}$ period). Numerous previous experiments have shown that these neurons are inhibited by dopaminergic agonists via D2 receptors and are therefore considered as DA. Neurons whose firing frequency varied by more than $5 \%$ in control conditions were discarded. To quantify the effect of various concentrations of XG on the firing frequency, we calculated the mean frequency of each neuron over a 5-min control period. We next measured the mean frequency of the neuron during the last minute of superfusion of a given drug concentration and calculated the ratio of the two values as a percentage. Due to the difficulty of solubilizing XG-carbonate, each neuron was exposed to only one concentration of that salt. Briefly, the ACSF had to be brought to a $\mathrm{pH}$ of $\sim 3$ for a full dissolution to occur. The $\mathrm{pH}$ was then brought back to 7.4 while the ACSF was oxygenated with carbogen and heated. In order to exclude artifacts related to $\mathrm{pH}$ manipulations, a control solution that did not contain the drug was prepared in parallel and superfused as the control solution. On the other hand, XG-mesylate solubilized easily at physiological $\mathrm{pH}$. Therefore, each neuron was exposed to various concentrations of this salt. To quantify firing regularity in the DAT KO experiments, we measured the $\mathrm{CV}_{\text {ISI }}$ defined as followed: $\mathrm{CV}_{\text {ISI }}=\mathrm{SD}_{\text {ISI }} /$ mean $_{\text {ISI. }}$. $\mathrm{CV}_{\text {ISI }}$ was measured during the control period for $5 \mathrm{~min}$, before superfusion of XG.

Extracellular recordings were also performed on noradrenergic neurons of the locus coeruleus (LC). The methods used to isolate LC were described previously (Meyrath et al., 2020; Seutin et al., 1989): slices were coronal at the level of the 4th ventricle where the LC could be visualized using a dissection microscope as a semi-lucent oval area lateral to the 4th ventricle and internal to the nucleus of the trigeminal nerve. Only neurons displaying a slow pacemaking $(0.5-3 \mathrm{~Hz})$ were used. They displayed a typical long duration action potential.

For whole-cell patch-clamp recordings, slices were positioned in the recording chamber and superfused with heated ACSF $\left(34^{\circ} \mathrm{C}\right)$. Neurons were visualized using infrared-Dodt gradient contrast (IR-DGC) optics on a Zeiss Axio Examiner A1 microscope equipped with a CCD camera (C7500-51; Hammamatsu, Japan). Patch pipettes (3-5 M 2 ) were pulled from filamented borosilicate glass tubing ( $2.0 \mathrm{~mm}$ outer diameter, 0.42 mm wall thickness; Reference 1403516, Hilgenberg, Germany) with a horizontal puller (P-97; Sutter Instruments, Novato, CA, USA). Pipettes were filled with a potassium gluconate-based solution, consisting of (in $\mathrm{mM}$ ): $125 \mathrm{~K}$-gluconate, $20 \mathrm{KCl}, 10$ HEPES, $4 \mathrm{Mg}$-ATP, $0.3 \mathrm{Na}$-GTP, 10 $\mathrm{Na}_{2}$-phosphocreatine, and 0.5 EGTA, pH $7.2(\sim 300 \mathrm{mosm} / \mathrm{L})$. Patchclamp recordings were performed using a Multiclamp $700 \mathrm{~B}$ amplifier connected to a PC through a Digidata 1550 interface (Molecular Devices, San Jose, CA, USA) and we acquired data with pClamp 10.5 (Molecular Devices). Data were sampled at $50 \mathrm{kHz}$ and filtered at $10 \mathrm{kHz}$ through a Bessel filter. Some traces in the figures were digitally filtered at $2 \mathrm{kHz}$ (Gaussian characteristics). Analyses were carried out in pClamp 10.5 (clampFit) or Stimfit 0.15 (Christoph Schmidt-Hieber, UCL).

SNc DA neurons were identified based on their electrophysiological properties, including low frequency of firing $(0.5-5 \mathrm{~Hz})$, AP duration (width at half-amplitude $>1.35 \mathrm{~ms}$ ) and the presence of a strong hyperpolarization-activated inward current $\left(\mathrm{I}_{\mathrm{h}}\right)$ (Fig. S1) (Richards 
et al., 1997; Seutin and Engel, 2010). Burst recordings were performed as previously described (Destreel et al., 2019; Johnson et al., 1992).

Intracellular application of XG mesylate was done by adding it to the intracellular solution. For these experiments, a neuron was first patched in the whole-cell configuration with the control intracellular solution to check its DA nature (see above) and record its basal spontaneous activity. Then, the pipette was withdrawn from the neuron and the neuron was patched with a second pipette containing the drug.

The experiments on $\mathrm{I}_{\mathrm{h}}$ activation were performed in the presence of $1 \mu \mathrm{M}$ tetrodotoxin (TTX) and $200 \mu \mathrm{M} \mathrm{Cd}^{2+}$. Experiments on $\mathrm{I}_{\mathrm{A}}$ activation and inactivation were done in the presence of these two blockers plus 20 $\mathrm{mM}$ TEA and $2.5 \mathrm{mM} \mathrm{Cs}^{+}$.

For pacemaker clamp recordings, patch pipettes had a very low resistance (1-3 M $\Omega$ ) and various solutions were used to determine the ionic nature of $I_{X G}$. For the external solution, we first used the standard ACSF solution (see above). The low $\mathrm{Ca}^{2+}$ solution contained $0.1 \mathrm{mM}$ $\mathrm{CaCl}_{2}$; for the high choline solution, we replaced $\mathrm{NaCl}$ equimolarly by choline chloride. For the internal solution, we used a potassium gluconate-based solution (as described above), a cesium gluconatebased solution, in which $\mathrm{K}$-gluconate and $\mathrm{KCl}$ were replaced equimolarly by Cs-gluconate and $\mathrm{CsCl}$, respectively and a potassium chloride-based solution in which $\mathrm{K}$ gluconate was replaced by $\mathrm{KCl}$, giving a total intracellular concentration of $145 \mathrm{mM} \mathrm{KCl}$. Recordings in which access resistance increased by $>20 \%$ over the duration of the recording were discarded. All the experiments described above, except bursting activity recordings, were performed in the presence of synaptic blockers to isolate DA neurons pharmacologically and to prevent any presynaptic effect. We used $10 \mu \mathrm{M}$ CNQX, $10 \mu \mathrm{M}$ SR95531, $1 \mu \mathrm{M}$ MK801, $1 \mu \mathrm{M}$ sulpiride, and $1 \mu \mathrm{M}$ CGP55845, to block respectively AMPA/kainate, $\mathrm{GABA}_{\mathrm{A}}, \mathrm{NMDA}, \mathrm{D}_{2} / \mathrm{D}_{3}$, and $\mathrm{GABA}_{\mathrm{B}}$ receptors. In the case of LC neurons, sulpiride was replaced by $10 \mu \mathrm{M}$ yohimbine in 3 out of 6 experiments. Since the results of the experiments were identical, results were pooled.

For cell-attached recordings, $250 \mu \mathrm{m}$-thick coronal midbrain slices were obtained from 10 to 12 -week-old male C57BL/6 N mice. Animals were sectioned in ice-cold ACSF (containing in mM: 50 sucrose, 125 $\mathrm{NaCl}, 2.5 \mathrm{KCl}, 25 \mathrm{NaHCO}_{3}, 1.25 \mathrm{NaH}_{2} \mathrm{PO}_{4}, 2.5$ glucose, $6.2 \mathrm{MgCl}_{2}, 0.1$ $\mathrm{CaCl}_{2}$, and 3 kynurenic acid; Sigma-Aldrich $\mathrm{GmbH}$; bubbled with $95 \%$ $\mathrm{O}_{2} / 5 \% \mathrm{CO}_{2}$ ) after intracardial perfusion with ice-cold ASCF. After sectioning, slices were rested for recovery at least $1 \mathrm{~h}$ before recording in $95 \% \mathrm{O}_{2} / 5 \% \mathrm{CO}_{2} \mathrm{ACSF}$ at $37{ }^{\circ} \mathrm{C}$. Recordings were carried out in ACSF (containing in mM: 22.5 sucrose, $125 \mathrm{NaCl}, 2.5 \mathrm{KCl}, 25 \mathrm{NaHCO}_{3}, 1.25$ $\mathrm{NaH}_{2} \mathrm{PO}_{4}, 2.5$ glucose, $2 \mathrm{MgCl}_{2}, 2 \mathrm{CaCl}_{2}$; bubbled with $95 \% \mathrm{O}_{2} / 5 \% \mathrm{CO}_{2}$ in the presence of CNQX $(20 \mu \mathrm{M})$, DL-AP-5 $(4 \mu \mathrm{M})$ and Gabazine (SR95531, $4 \mu \mathrm{M}$ ) to inhibit fast excitatory and inhibitory transmission. DA SNc neurons were initially visually identified and recorded in cellattached mode and subsequently in whole-cell using a pipette solution containing in mM: $135 \mathrm{~K}$-gluconate, $10 \mathrm{HEPES}, 5 \mathrm{KCl}, 5 \mathrm{MgCl}_{2}, 0.075$ $\mathrm{CaCl}_{2}$, 0.1 EGTA, 5 ATP, 1 GTP, $0.1 \%$ neurobiotin.

Human NALCN, UNC79, UNC80, FAM155A complementary DNAs (cDNAs), codon optimized for Homo sapiens in pCDNA3.1(+) vectors, were used as previously described (Chua et al., 2020). The NALCN, UNC-79, UNC-80, and FAM155A RNAs were mixed in a ratio of 1:1:1:1 and injected into Xenopus laevis oocytes. Injected cells were incubated in ND96 (96 mM NaCl, $2 \mathrm{mM} \mathrm{KCl,} 1 \mathrm{mM} \mathrm{MgCl}_{2}, 1.8 \mathrm{mM} \mathrm{CaCl}_{2}$, and $5 \mathrm{mM}$ HEPES; pH 7.4) supplemented with $0.5 \mathrm{mM}$ theophylline, $2.5 \mathrm{mM} \mathrm{Na}$ pyruvate, $50 \mu \mathrm{g} / \mathrm{mL}$ gentamycin and $50 \mu \mathrm{g} / \mathrm{mL}$ tetracycline at $18{ }^{\circ} \mathrm{C}$, $140 \mathrm{rpm}$. Two-electrode voltage-clamp measurements were performed on oocytes five days after injection using a Warner OC-725C Oocyte Clamp amplifier (Warner Instrument Corp, USA). Oocytes were continuously superfused by a $\mathrm{Ca}^{2+} / \mathrm{Mg}^{2+}$-free ND96 recording solution (96 $\mathrm{mM} \mathrm{NaCl}, 2 \mathrm{mM} \mathrm{KCl}, 2 \mathrm{mM} \mathrm{BaCl}_{2}$, and $5 \mathrm{mM}$ HEPES; $\mathrm{pH} 7.4$ ) at room temperature. Data were acquired using the pCLAMP 10 software (Molecular Devices) and a Digidata 1550 digitizer (Molecular devices), sampled at $10 \mathrm{kHz}$. Electrical powerline interference was filtered with a Hum Bug 50/60 Hz Noise Eliminator (Quest Scientific). Recording microelectrodes with resistances around 0.2-1.0 $\mathrm{M} \Omega$ were pulled from borosilicate glass capillaries (Harvard Apparatus) using a P-1000 Flaming/Brown Micropipette Puller System (Sutter Instrument) and were filled with $3 \mathrm{M} \mathrm{KCl}$. Stock solutions $(1 \mathrm{M})$ of gadolinium $\left(\mathrm{Gd}^{3+}\right.$, Sigma Aldrich) and XG-mesylate were prepared in $\mathrm{Ca}^{2+} / \mathrm{Mg}^{2+}$-free ND96 and diluted to desired concentrations.

\subsection{Immunofluorescence \& confocal microscopy}

Cell-attached recordings were converted to the whole-cell configuration to fill neurons with $0,1 \%$ neurobiotin for post-hoc verification of anatomical and neurochemical identity. The slices were then fixed in $4 \%$ PFA-PBS solution (containing 15\% Picric acid, $0.1 \mathrm{M}$ buffer, $\mathrm{pH}=7.4$ ) overnight at $4{ }^{\circ} \mathrm{C}$, rinsed in PBS (containing in $\mathrm{mM}$ : $137 \mathrm{NaCl} ; 2.7 \mathrm{KCl}$; $10 \mathrm{NaH}_{2} \mathrm{PO}_{4} ; 10 \mathrm{Na}_{2} \mathrm{HPO}_{4} ; \mathrm{pH}=7.4$ ) and incubated in blocking solution (0.2 M PBS with $10 \%$ horse serum, $0.5 \%$ Triton X-100, $0.2 \%$ BSA) for 1 h. Slices were incubated with polyclonal anti-tyrosine hydroxylase rabbit antibodies (1:1000, Calbiochem, Merck) and were incubated overnight in carrier solution (containing in PBS: $0.2 \% \mathrm{BSA}, 0.5 \%$ Triton, $1 \%$ horse serum) at room temperature. Slices were again rinsed in PBS and incubated in carrier solution with an AlexaFluor-568 secondary anti-rabbit polyclonal goat antibody (1:1000; Thermo Fisher Scientific) and Streptavidin AlexaFluor-488 (1:750; Thermo Fisher Scientific) overnight, then rinsed and mounted in Vectashield. Confocal microscopy was used to identify recorded neurons as dopaminergic and locate the position of neurobiotin-positive recorded neurons inside the SNc.

\subsection{Synthesis of $X G$-mesylate}

\subsection{1. $N, N^{\prime}$-diBOC-2,4-Xylyl Guanidine (BOC-XG) preparation}

2,4-dimethylaniline (about $50 \mathrm{mmol}$ ) reacted overnight with $\mathrm{N}, \mathrm{N}^{\prime}$ diBOC-1H-pyrazole-1-carboxamidine (1.2 equivalents) as well as $\mathrm{N}$ ethyldiisopropylamine (2 equivalents) in $100 \mathrm{ml}$ of methanol. The reaction medium was then evaporated under reduced pressure. The resulting crude oil was dissolved in $100 \mathrm{ml}$ ethyl acetate and washed three times by $30 \mathrm{ml} \mathrm{HCl}(1 \mathrm{~N})$ and by $50 \mathrm{ml}$ brine. The organic solution was evaporated under reduced pressure, and the residue was then crystallized in methanol.

${ }^{1} \mathrm{H} \mathrm{NMR}\left(\mathrm{CDCl}_{3}, 500 \mathrm{MHz}\right) \delta(\mathrm{ppm}) 1.47(\mathrm{~s}, 10 \mathrm{H}), 1.54(\mathrm{~s}, 10 \mathrm{H}), 2.26$ (s, 3H), 2.28 (s, 3H), 7.00 (m, 2H), 7.75 (d, $J=8.14 \mathrm{~Hz}, 1 \mathrm{H}), 10.04$ (s, $1 \mathrm{H}), 11.67(\mathrm{~s}, 1 \mathrm{H})$

${ }^{13} \mathrm{C}$ NMR: $\left(\mathrm{CDCl}_{3}, 500 \mathrm{MHz}\right) \delta(\mathrm{ppm})\left(\mathrm{CH}_{3}\right) 18.13,20.82,28.10$, 28.22, (CH)124.64, 127.06, 130.95, (C) 79.38, 83.42, 130.35, 132.49, 134.96, 153.44, 154.03, 163.78.

Elemental Analysis: $\mathrm{C}_{19} \mathrm{H}_{29} \mathrm{~N}_{3} \mathrm{O}_{4}(363.46 \mathrm{~g} / \mathrm{mol})$ Calculated (\%) C 62.79, H 8.04, N 11.56, Found (\%) C 62.58, H 8.28, N 11.63.

\subsubsection{2,4-Xylyl Guanidine mesylate (XG mesylate) preparation}

The isolated BOC-XG was dissolved in $50 \mathrm{ml}$ dichloromethane and methanesulfonic acid ( $2.5 \mathrm{ml}$ per gram) was added. After $4-5 \mathrm{~h}$ at room temperature, the medium was evaporated under reduced pressure, the oily residue was subsequently washed five times by about $20 \mathrm{ml}$ diisopropylether and dried under reduced pressure. The XG mesylate was then crystallized in hot ethanol by addition of cold diethylether.

${ }^{1}$ H NMR: $\left(\mathrm{CDCl}_{3}, 500 \mathrm{MHz}\right) \delta(\mathrm{ppm}) 2.27(\mathrm{~s}, 3 \mathrm{H}), 2.32(\mathrm{~s}, 3 \mathrm{H}), 2.85$ (s, 3H), 7.07 (m, 3H), 7.58 (broad, 3H), $9.28(\mathrm{~s}, 1 \mathrm{H})$

${ }^{13} \mathrm{C}$ NMR: $\left(\mathrm{CDCl}_{3}, 500 \mathrm{MHz}\right) \delta(\mathrm{ppm})\left(\mathrm{CH}_{3}\right) 17.18,20.88,39.22,(\mathrm{CH})$ 127.46, 128.00, 132.36, (C) 129.80, 135.96, 138.88, 156.93.

Melting point: $105.5-107.5{ }^{\circ} \mathrm{C}$ (several samples presented another polymorphic form, confirmed by Raman and FTIR spectra, and a melting point at $137.5-139.0{ }^{\circ} \mathrm{C}$ )

Elemental Analysis: $\mathrm{C}_{10} \mathrm{H}_{17} \mathrm{~N}_{3} \mathrm{O}_{3} \mathrm{~S}(259.33 \mathrm{~g} / \mathrm{mol})$ Calculated (\%) C 46.32, H 6.61, N 16.20, S 12.36 Found (\%) C 46.33, H 6.70, N 16.25, S 12.02 .

Mass Spectrometry: $\mathrm{C}_{9} \mathrm{H}_{13} \mathrm{~N}_{3}(163.11 \mathrm{~g} / \mathrm{mol})$ Adduct $+\mathrm{H}^{+}$, extraction mass 164.11822 Da, found at 164.11817 Da. 


\subsection{Statistics}

Data are presented as mean \pm standard error of the mean (SEM). Statistical analyses were performed using Prism 8 . Normality tests were performed prior to analyzing the data by either a parametric or nonparametric test. Depending on the distribution of the data and the number of groups to compare, we used a Student's t-test, a Wilcoxon test, an ANOVA-1/Friedman test followed by a post hoc Holm-Sidak's or Dunn's test, or an ANOVA-2 test. Significance level is given as * $<0.05$, $* *<0.01, * * *<0.001, * * * *<0.0001$ and is displayed in the figures.

\subsection{Chemicals}

Apamin, CNQX and SR9551 were purchased from Alomone labs (Jerusalem, Israel); isradipine, ZD 7228, MK801, NMDA, sulpiride and CGP55845 from Tocris Bioscience (Bristol, UK); TTX and Cs-gluconate from Hello Bio (Bristol, UK); 4-AP, nifedipine, XG carbonate and salts used to prepare the external and internal solutions were obtained from Sigma-Aldrich (Overijse, Belgium).

\section{Results}

3.1. XG selectively inhibits the slow pacemaker activity of DA neurons across the entire midbrain

We first performed extracellular recordings on acute SNc slices from adult rats to investigate the effect of XG on the spontaneous activity on DA neurons. We applied synaptic blockers $(10 \mu \mathrm{M}$ CNQX, $1 \mu \mathrm{M}$ MK-801, $1 \mu \mathrm{M}$ CGP55845, $10 \mu \mathrm{M}$ SR9551 and $1 \mu \mathrm{M}$ sulpiride) before and during the superfusion of XG to prevent any presynaptic effect of the compound. We observed that application of $2 \mathrm{mM} \mathrm{XG}$ stops the firing of these neurons (Fig. 1B). We then tested lower concentrations of XG (Fig. 1C and found that the compound inhibits the spontaneous firing of DA neurons in a concentration-dependent manner with an $\mathrm{IC}_{50}$ of $486 \pm 51$ $\mu \mathrm{M}(\mathrm{n}=6$ for each concentration; Fig. 1D) and a Hill slope of $1.28 \pm$ 0.19 . This result is consistent with the pharmacology of $I_{\omega}$ (Sokolov et al., 2010) and indicates that the inhibition is probably due to the interaction of XG with a single target. Since the carbonate salt of XG, which was used in these experiments, is difficult to solubilize at physiological $\mathrm{pH}$, we synthetized a mesylate salt of $\mathrm{XG}$ which is much easier to use. We performed the same experiments with this compound and obtained an $\mathrm{IC}_{50}$ of $427 \pm 43 \mu \mathrm{M}$, which is not significantly different from the one of the carbonate salt $(n=6$ for each condition, $F(1,56)=0.6828$, $\mathrm{p}=0.4121$, extra sum-of-squares $\mathrm{F}$ test; Fig. 1D). The Hill slope was

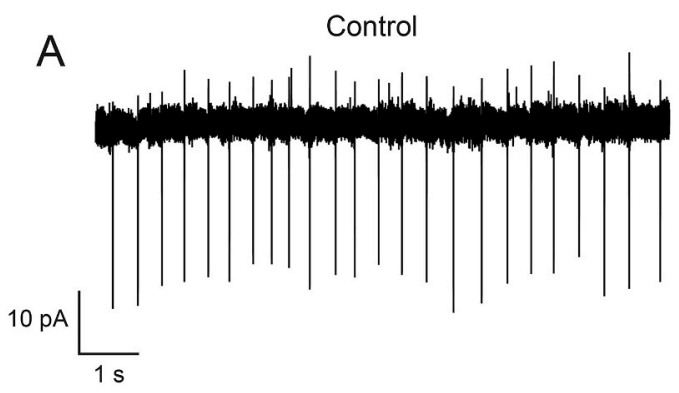

Control

$2 \mathrm{mM} \times \mathrm{G}$

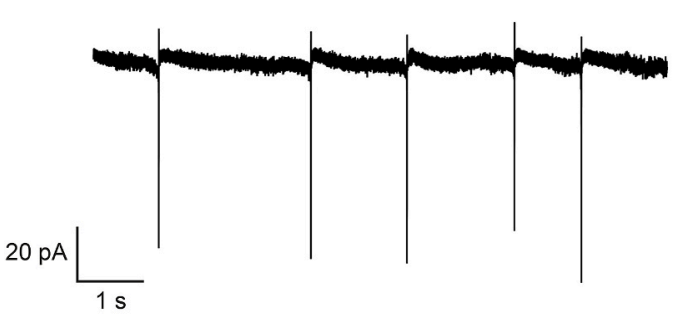

C

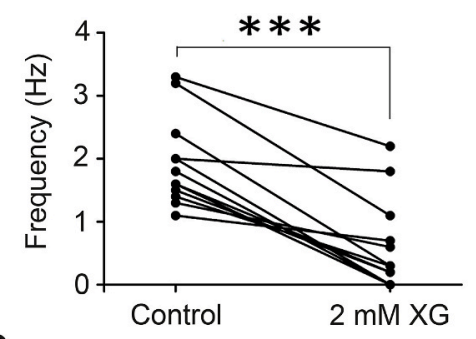

D

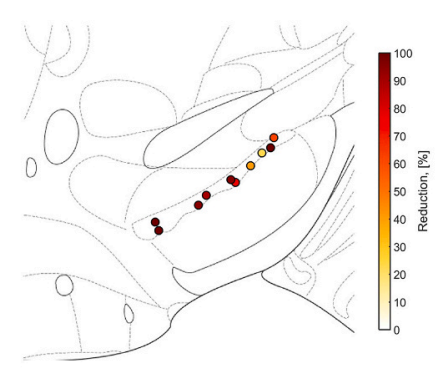

E

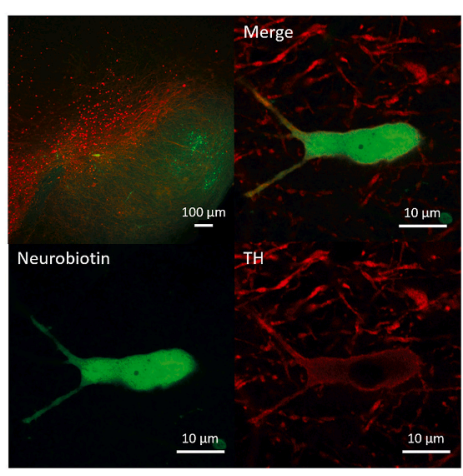

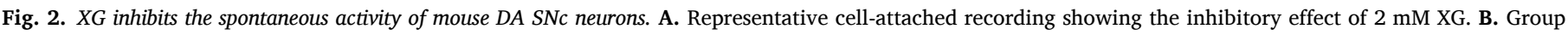

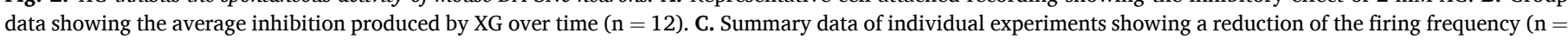

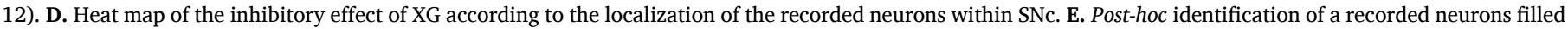
with neurobiotin as being DA based on TH immunofluorescence. 
$1.27 \pm 0.15$. Interestingly, we obtained similar results on DA neurons located in the ventral tegmental area (VTA) using the mesylate salt of XG. These experiments yielded an $\mathrm{IC}_{50}$ for the blocker of $332.5 \pm 95 \mu \mathrm{M}$ and a Hill slope of $1.05 \pm 0.28(\mathrm{n}=6$ for each condition, $\mathrm{F}(1,68)=$ $2.108, \mathrm{p}=0.1511$, extra sum-of-squares $\mathrm{F}$ test; Fig. $1 \mathrm{D}$ ). In order to assess the degree of specificity of the effect of XG, we tested its effect on noradrenergic neurons of the LC, which are also slow pacemakers, but slightly less regular than DA neurons. XG did not affect the pacemaking frequency of these neurons $(1.46 \pm 0.13 \mathrm{~Hz}$ in control vs $1.50 \pm 0.08 \mathrm{~Hz}$ in $2 \mathrm{mM} \mathrm{XG}, \mathrm{n}=6, \mathrm{t}(5)=0.2734, \mathrm{p}=0.7955$, $t$-test; Fig. $1 \mathrm{E}$ and $\mathrm{F}$ ).

We also carried out cell-attached recordings on synaptically isolated mouse DA SNc neurons to verify whether the pacemaker inhibition by $\mathrm{XG}$ is species-dependent. We applied $2 \mathrm{mM} \mathrm{XG}$ after a stable baseline of spontaneous discharge was established (Fig. 2A and B). After $>10 \mathrm{~min}$, we opened the cells to the whole-cell configuration in order to fill the neuron with neurobiotin for post-hoc immunofluorescence identification (Fig. 2E). We observed a strong reduction of firing frequency (1.94 $\pm 0.22 \mathrm{~Hz}$ in control vs $0.54 \pm 0.20 \mathrm{~Hz}$ in $2 \mathrm{mM} \mathrm{XG}, \mathrm{n}=12, \mathrm{p}=0.0005$, Wilcoxon test; Fig. 2C) across the entire SNc (Fig. 2D). These results indicate that the pacemaker inhibition by XG in DA SNc neurons is similar in both rats and mice.

Taken together, these results demonstrate that XG specifically inhibits pacemaking of DA neurons in two rodent species and at two different ages. In addition, since two different salts of XG yielded similar results, we conclude that the xylylguanidinium moiety is responsible for the observed effect.

\subsection{Mechanism of action of XG on SNc DA neurons}

We next investigated the mechanism of action of XG on DA neurons using whole-cell patch-clamp. These neurons were identified as described in the methods (Fig. S1). In line with our previous experiments, extracellular application of XG was able to halt the spontaneous activity of DA SNc neurons $(1.94 \pm 0.18 \mathrm{~Hz}$ in control vs $0.02 \pm 0.001$ $\mathrm{Hz}$ in $2 \mathrm{mM} \mathrm{XG}, \mathrm{n}=8, \mathrm{p}=0.0078$, Wilcoxon test; Fig. 3A and $\mathrm{B}$ ). Intriguingly, intracellular application of $\mathrm{XG}$ also inhibited the pacemaking $(1.91 \pm 0.29 \mathrm{~Hz}$ in control vs $0.0003 \pm 0.0003 \mathrm{~Hz}$ during intracellular application of $2 \mathrm{mM} \mathrm{XG}, \mathrm{n}=6, \mathrm{p}=0.0312$, Wilcoxon test; Fig. 3C). We also tested $2 \mathrm{mM} \mathrm{XG}$ on GABA substantia nigra pars reticulata neurons, which are fast pacemaker neurons. XG did not significantly change the firing frequency of these neurons $(8.18 \pm 1.07$ $\mathrm{Hz}$ in control vs $8.52 \pm 1.06 \mathrm{~Hz}$ in $2 \mathrm{mM} \mathrm{XG}, \mathrm{n}=7, \mathrm{t}(6)=1.419, \mathrm{p}=$ $0.2057, t$-test; Fig. $3 \mathrm{~F}$ and G).

Importantly, the membrane potential of DA SNc neurons during XG

$$
\text { A }
$$

B

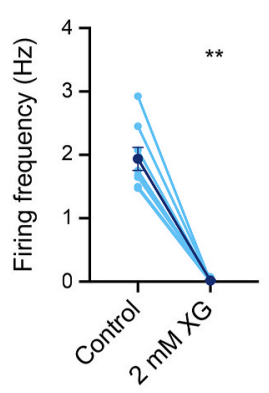

$\mathrm{F}$

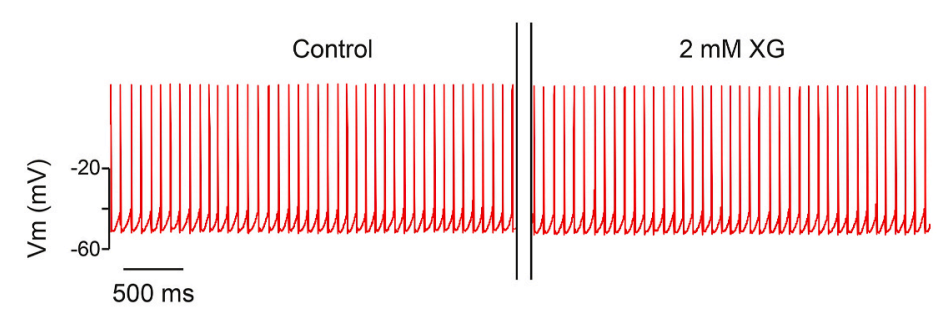

C

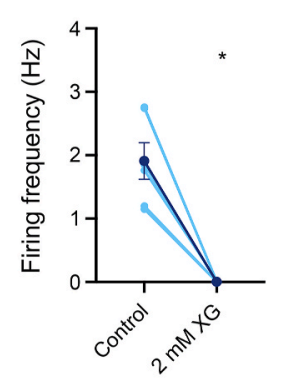

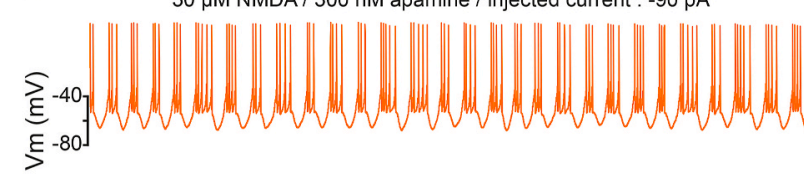
$30 \mu \mathrm{M}$ NMDA / $300 \mathrm{nM}$ apamine / 2 mM XG / injected current : -90 pA

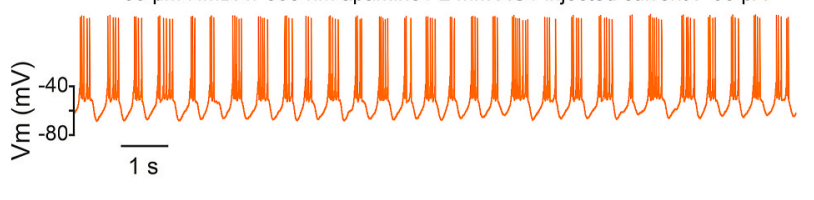

G

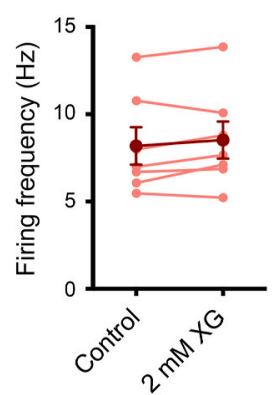

E

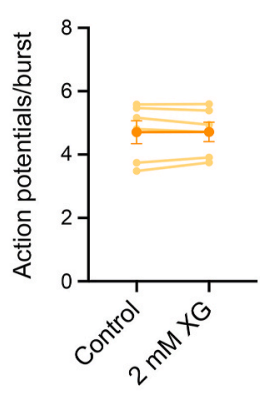

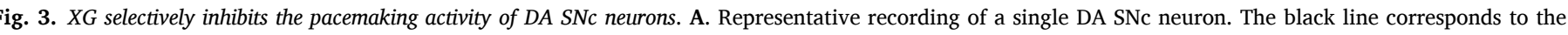

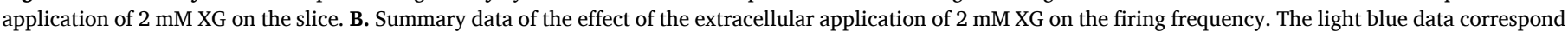

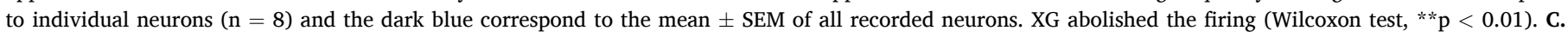

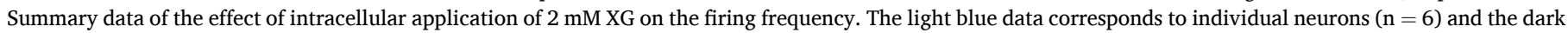

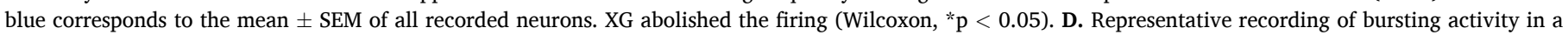

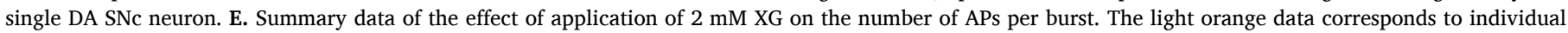

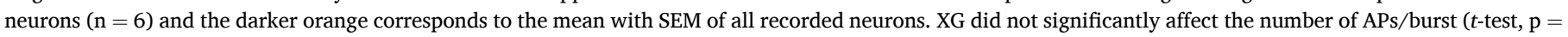

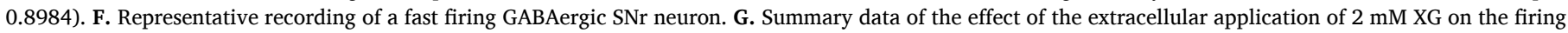

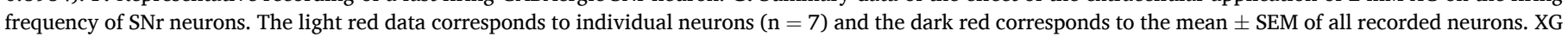

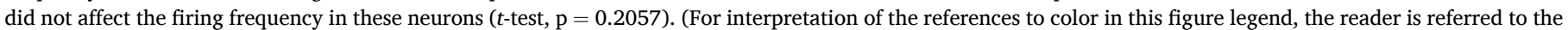
Web version of this article.) 
application stayed between -50 and $-55 \mathrm{mV}$, indicating that the inhibition is not due to a strong hyperpolarization of the neurons. This was confirmed in voltage clamp experiments, in which we clamped the cells at $-50 \mathrm{mV}$ and imposed a hyperpolarizing step to $-60 \mathrm{mV}$. The wholecell conductance was not affected by $2 \mathrm{mM} \mathrm{XG}(1.98 \pm 0.23 \mathrm{nS}$ in control, $1.97 \pm 0.23 \mathrm{nS}$ in the presence of the drug and $2.06 \pm 0.23 \mathrm{nS}$ during wash-out, $\mathrm{n}=8$ for each condition, $\mathrm{F}(1.779,12.46)=2.081, \mathrm{p}=$ 0.1686 , ANOVA-1; Fig. S2). The holding current at $-60 \mathrm{mV}$ was unaffected as well. Taken together, these experiments demonstrate that XG inhibits the slow pacemaking of DA neurons without opening ion channels.

Since DA neurons display two firing modes in vivo, we induced bursting activity by superfusing $30 \mu \mathrm{M}$ NMDA and $300 \mathrm{nM}$ apamin to block SK channels, while injecting a constant hyperpolarizing current (Destreel et al., 2019; Johnson et al., 1992) to test whether XG could modulate this firing mode. $2 \mathrm{mM}$ XG did not modify the bursting: the number of bursts per second and the number of APs per burst did not change in the presence of the drug ( $4.71 \pm 0.36$ in control vs $4.72 \pm 0.31$ in $2 \mathrm{mM} \mathrm{XG}, \mathrm{n}=6, \mathrm{t}(5)=0.1343, \mathrm{p}=0.8984$, $t$-test; Fig. 3D and $\mathrm{E}$ ). These observations demonstrate that XG selectively blocks pacemaking without interfering with other types of firing patterns such as bursting activity in DA SNc neurons. This further demonstrates the degree of selectivity of the drug on pacemaking of DA neurons.

When XG was applied on a pacemaking neuron, injection of a small positive current in the range of $10-30 \mathrm{pA}$ was able to reinstate action potential firing, indicating that the inhibition is not due to blockade of the main pore of $\mathrm{Na}_{\mathrm{v}}$ channels (Fig. 4A). We performed $10 \mathrm{pA}$ current steps from $0 \mathrm{pA}$ to $+50 \mathrm{pA}$ for $2 \mathrm{~s}$ to analyze three parameters of the AP: threshold, half-width and maximal slope. Application of $2 \mathrm{mM} \mathrm{XG}$ did not change the threshold $(\mathrm{p}=0.8774)$, the half-width $(\mathrm{p}=0.3022)$ or the maximal slope $(\mathrm{p}=0.3992)$ of the AP whatever the current amplitude ( $\mathrm{n}=5$ for all conditions, ANOVA-2; Fig. 4B, Table 1 ). We also performed $20 \mathrm{pA}$ steps from $0 \mathrm{pA}$ to $160 \mathrm{pA}$ for $2 \mathrm{~s}$ to determine the amplitude of the shift in current needed to generate pacemaking. The linear regression (Fig. 4C) of individual frequency-current curves shows that there was a shift from $-19.43 \pm 7.56 \mathrm{pA}$ in control to $4.46 \pm 2.32$ pA in $2 \mathrm{mM} \mathrm{XG}(\mathrm{n}=6, \mathrm{t}(5)=2.910, \mathrm{p}=0.0334$, $t$-test; Fig. 4E), indicating that the amplitude of the blocked current was $-23.89 \pm 8.21 \mathrm{pA}$. We also did not observe a significant change in the gain $(68.63 \pm 13.69$ $\mathrm{Hz} / \mathrm{nA}$ in control vs $84.79 \pm 11.60 \mathrm{~Hz} / \mathrm{nA}$ in $2 \mathrm{mM} \mathrm{XG}, \mathrm{n}=6, \mathrm{t}(5)=$ $1.353, \mathrm{p}=0.2341$, $t$-test; Fig. $4 \mathrm{D}$ ), which is consistent with the results from the action potential parameter characterization. These results demonstrate that the inhibition by XG is not due to the modulation of voltage-gated channels involved in AP generation but rather involves the blockade of a small but essential inward current in the subthreshold range.

\subsection{The XG-sensitive conductance is crucial for all oscillatory events, both in the absence and presence of tetrodotoxin}

Oscillatory events that are observed in DA neurons include the slow pacemaking in control conditions, but also slow membrane potential oscillations that can be observed when fast $\mathrm{Na}_{\mathrm{v}}$ channels are blocked by tetrodotoxin (TTX). We next investigated whether the XG-sensitive
A

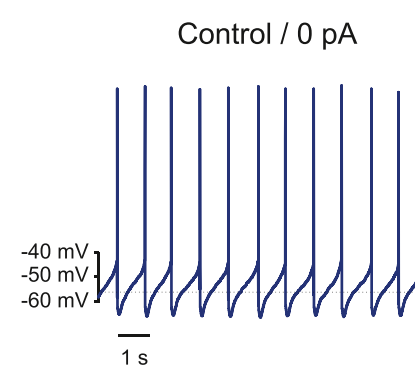

C

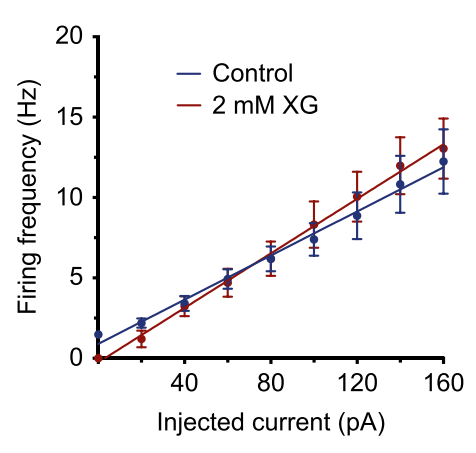

$2 \mathrm{mM} X \mathrm{XG} / 0 \mathrm{pA}$
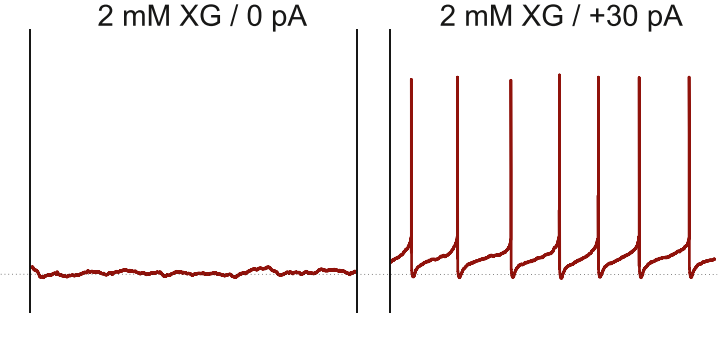

B

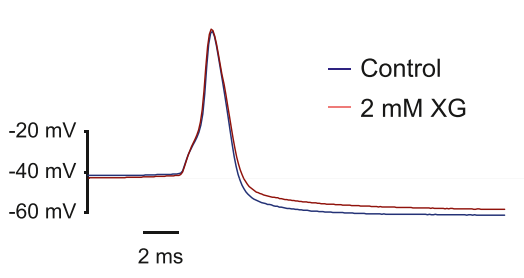

E

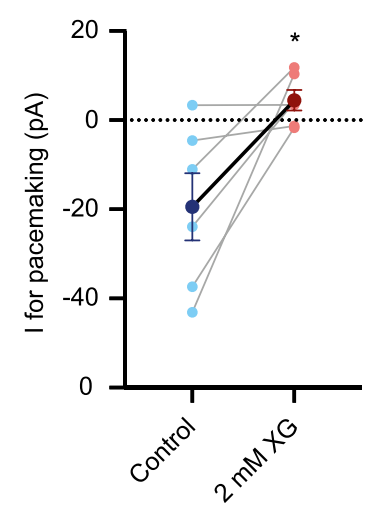

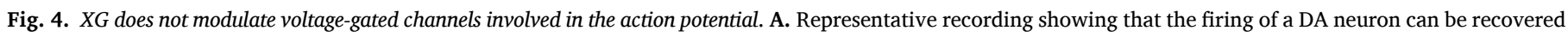

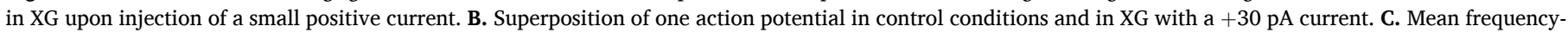

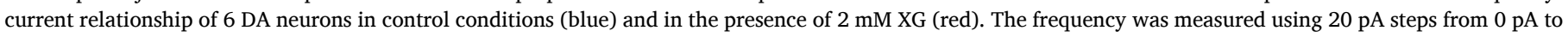

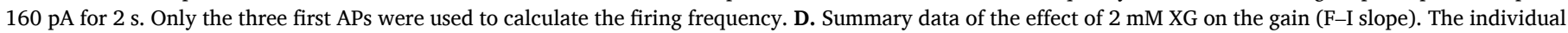

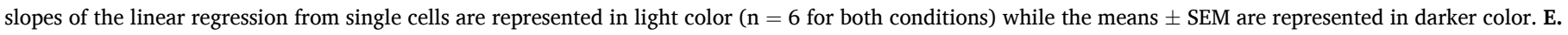

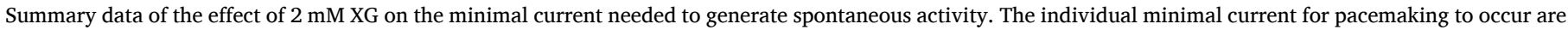

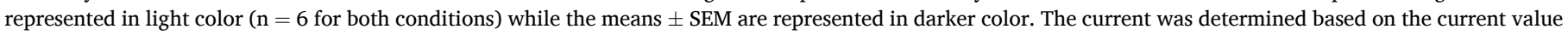

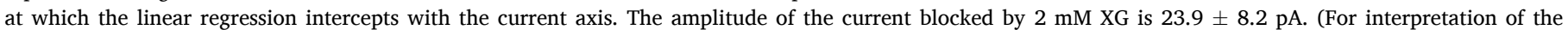
references to color in this figure legend, the reader is referred to the Web version of this article.) 
Table 1

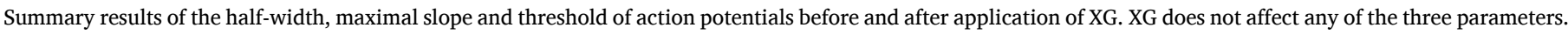

\begin{tabular}{|c|c|c|c|c|c|c|c|c|c|c|c|c|}
\hline & \multicolumn{2}{|l|}{$0 \mathrm{pA}$} & \multicolumn{2}{|l|}{$10 \mathrm{pA}$} & \multicolumn{2}{|l|}{$20 \mathrm{pA}$} & \multicolumn{2}{|l|}{$30 \mathrm{pA}$} & \multicolumn{2}{|l|}{$40 \mathrm{pA}$} & \multicolumn{2}{|l|}{$50 \mathrm{pA}$} \\
\hline & Control & $X G$ & Control & $X G$ & Control & $X G$ & Control & $X G$ & Control & $X G$ & Control & $X G$ \\
\hline $\begin{array}{l}\text { Half-width } \\
\quad \text { (ms) }\end{array}$ & $\begin{array}{l}2.00 \pm \\
0.25 \\
\mathrm{n}=5\end{array}$ & - & $\begin{array}{l}1.98 \pm \\
0.15 \\
\mathrm{n}=5\end{array}$ & $\begin{array}{l}1.98 \pm \\
0.19 \\
\mathrm{n}=4\end{array}$ & $\begin{array}{l}1.96 \pm \\
0.15 \\
\mathrm{n}=5\end{array}$ & $\begin{array}{l}2.17 \pm \\
0.17 \\
\mathrm{n}=5\end{array}$ & $\begin{array}{l}2.13 \pm 0.2 \\
\mathrm{n}=5\end{array}$ & $\begin{array}{l}2.23 \pm \\
0.17 \\
\mathrm{n}=5\end{array}$ & $\begin{array}{l}2.24 \pm \\
0.16 \\
\mathrm{n}=5\end{array}$ & $\begin{array}{l}2.33 \pm \\
0.13 \\
\mathrm{n}=5\end{array}$ & $\begin{array}{l}2.14 \pm \\
0.21 \\
\mathrm{n}=5\end{array}$ & $\begin{array}{l}2.32 \pm \\
0.16 \\
\mathrm{n}=5\end{array}$ \\
\hline $\begin{array}{l}\text { Max slope } \\
\text { (ms) }\end{array}$ & $\begin{array}{l}83.44 \pm \\
10.47 \\
\mathrm{n}=5\end{array}$ & - & $\begin{array}{l}79.04 \pm \\
8.33 \\
n=5\end{array}$ & $\begin{array}{l}92.12 \pm \\
11.38 \\
\mathrm{n}=4\end{array}$ & $\begin{array}{l}74.40 \pm \\
7.49 \\
\mathrm{n}=5\end{array}$ & $\begin{array}{l}78.67 \pm \\
11.87 \\
n=5\end{array}$ & $\begin{array}{l}69.79 \pm \\
7.04 \\
n=5\end{array}$ & $\begin{array}{l}74.34 \pm \\
10.88 \\
\mathrm{n}=5\end{array}$ & $\begin{array}{l}60.00 \pm \\
7.38 \\
\mathrm{n}=5\end{array}$ & $\begin{array}{l}68.97 \pm \\
9.82 \\
n=5\end{array}$ & $\begin{array}{l}65.31 \pm \\
5.16 \\
n=5\end{array}$ & $\begin{array}{l}58.17 \pm \\
7.33 \\
\mathrm{n}=5\end{array}$ \\
\hline $\begin{array}{l}\text { Threshold } \\
(\mathrm{mV})\end{array}$ & $\begin{array}{l}-35.13 \pm \\
1.90 \\
\mathrm{n}=5\end{array}$ & - & $\begin{array}{l}-33.86 \pm \\
2.34 \\
\mathrm{n}=5\end{array}$ & $\begin{array}{l}-35.64 \pm \\
2.71 \\
n=4\end{array}$ & $\begin{array}{l}-34.05 \pm \\
1.98 \\
\mathrm{n}=5\end{array}$ & $\begin{array}{l}-33.32 \pm \\
2.54 \\
\mathrm{n}=5\end{array}$ & $\begin{array}{l}-32.65 \pm \\
2.13 \\
\mathrm{n}=5\end{array}$ & $\begin{array}{l}-32.46 \pm \\
2.91 \\
\mathrm{n}=5\end{array}$ & $\begin{array}{l}-31.57 \pm \\
2.43 \\
\mathrm{n}=5\end{array}$ & $\begin{array}{l}-32.53 \pm \\
1.83 \\
\mathrm{n}=5\end{array}$ & $\begin{array}{l}-32.62 \pm \\
1.81 \\
\mathrm{n}=5\end{array}$ & $\begin{array}{l}-39.68 \pm \\
2.01 \\
\mathrm{n}=5\end{array}$ \\
\hline
\end{tabular}

conductance also enables these different oscillatory behaviors in DA neurons. We first studied autonomous oscillations by applying $1 \mu \mathrm{M}$ TTX (Fig. 5A). As previously shown by others (Guzman et al., 2009; Sun et al., 2017), we found that these oscillations are blocked by $5 \mu \mathrm{M}$ nifedipine, suggesting that they are mediated by L-type $\mathrm{Ca}_{\mathrm{v}}$ channels (Fig. 5A). Application of $2 \mathrm{mM}$ XG led to a complete silencing of these oscillations in all cases $(n=6$; Fig. $5 B)$. We then investigated whether XG could still inhibit pacemaker activity in the absence of L-type $\mathrm{Ca}_{\mathrm{V}}$-mediated oscillations. We applied $5 \mu \mathrm{M}$ nifedipine to block the latter and did not observe a significant change in the firing frequency $(1.96 \pm 0.22 \mathrm{~Hz}$ in control vs $1.79 \pm 0.18 \mathrm{~Hz}$ in $5 \mu \mathrm{M}$ nifedipine, $\mathrm{n}=6, \mathrm{p}=0.2482$, Friedman test; Fig. 5 c,d). These results are consistent with the literature (Drion et al., 2011; Guzman et al., 2009). Application of 2 mM XG led also to an almost complete inhibition of the spontaneous activity of DA
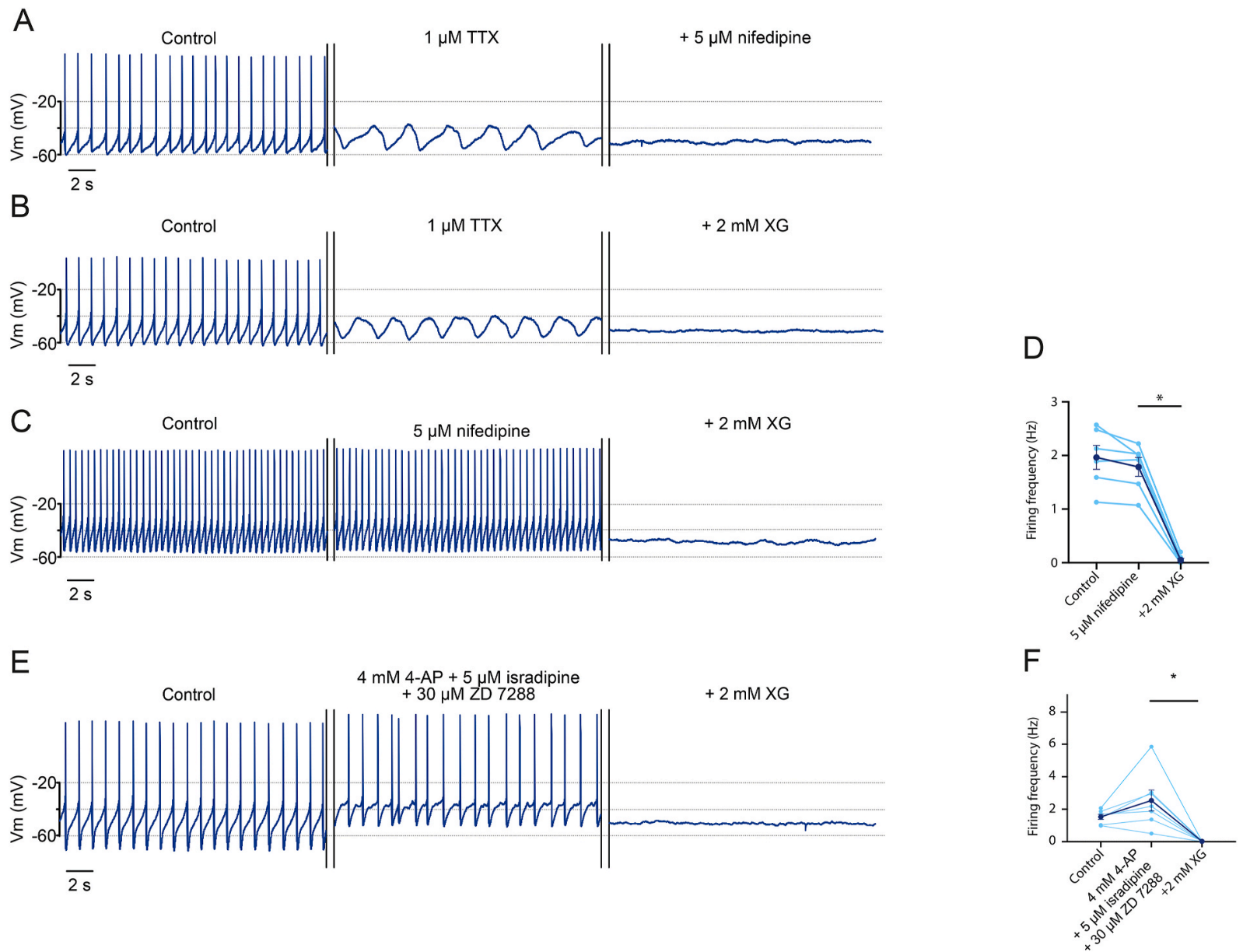

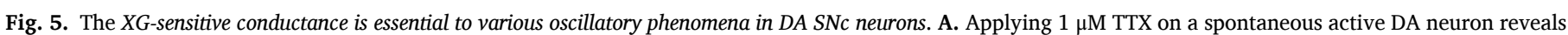

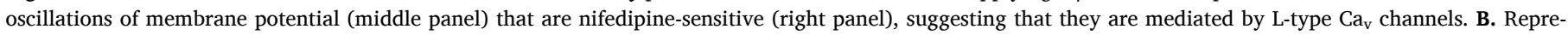

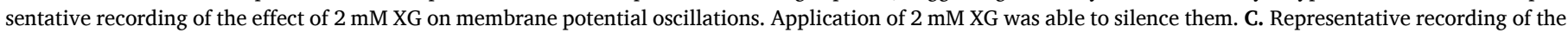

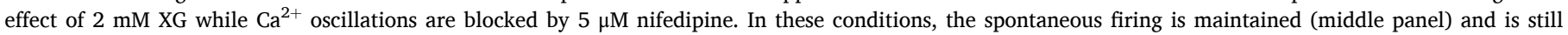

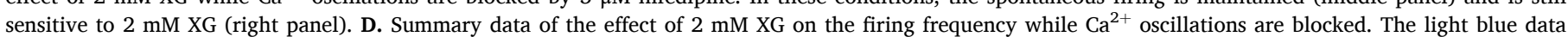

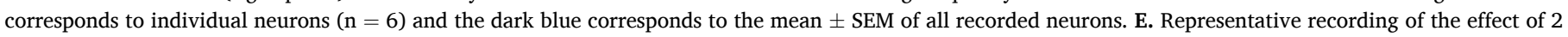

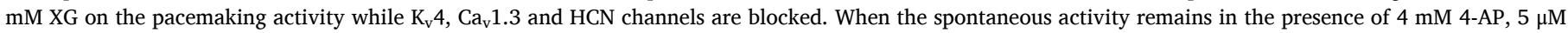

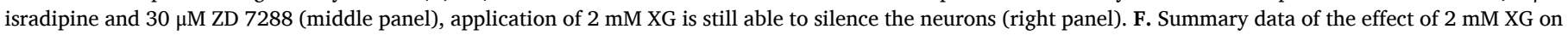

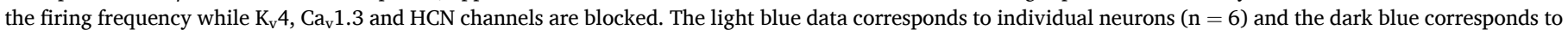

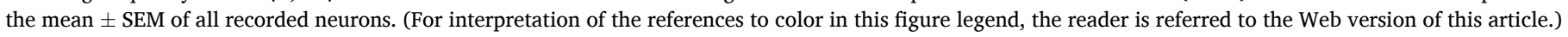


SNc neurons $(0.05 \pm 0.03 \mathrm{~Hz}$ in $5 \mu \mathrm{M}$ nifedipine $+2 \mathrm{mM}$ XG vs $1.78 \pm$ $0.18 \mathrm{~Hz}$ in $5 \mu \mathrm{M}$ nifedipine only, $\mathrm{p}=0.0433$, Friedman test; Fig. $5 \mathrm{C}$ and D). These data strongly suggest that an XG-sensitive current is crucial to enable various types of depolarizing channels to drive oscillatory events in these neurons.

Given that the robustness of the pacemaking activity in DA neurons may involve a cooperation between $\mathrm{K}_{\mathrm{v}} 4, \mathrm{Ca}_{\mathrm{v}} 1.3$ and $\mathrm{HCN}$ channels, we next investigated whether blocking all three categories of channels would impact the spontaneous activity of DA SNc and whether XG would still silence them. Application of $4 \mathrm{mM}$ 4-aminopyridine (4-AP), $5 \mu \mathrm{M}$ isradipine and $30 \mu \mathrm{M}$ ZD 7288 to block $\mathrm{K}_{\mathrm{v}} 4, \mathrm{Ca}_{\mathrm{v}} 1.3$ and HCN channels, respectively, did not significantly change the firing frequency $(1.53 \pm 0.15 \mathrm{~Hz}$ in control vs $2.54 \pm 0.64 \mathrm{~Hz}$ in $4 \mathrm{mM}$ 4-AP, $5 \mu \mathrm{M}$ isradipine and $30 \mu \mathrm{M}$ ZD 7288, $\mathrm{n}=6$ for each condition, $\mathrm{F}(1.041,6.245)$ $=13.48, \mathrm{p}=0.10$, ANOVA-1, Fig. $5 \mathrm{E}$ and F) while adding $2 \mathrm{mM}$ XG to the blockers abolished the firing of DA neurons $(0.02 \pm 0.01 \mathrm{~Hz}$ in blockers $+2 \mathrm{mM} \mathrm{XG}$, vs blockers, $\mathrm{n}=6$ for each condition, $\mathrm{F}(1.041$, $6.245)=13.48, p=0.02$, ANOVA-1, Fig. $5 \mathrm{E}$ and F). Furthermore, $2 \mathrm{mM}$ XG did not affect at all the kinetics of $\mathrm{I}_{\mathrm{A}}$ and $\mathrm{I}_{\mathrm{h}}$ (Figs. S3 and S4). Taken together, these data support the hypothesis that a specific XG-sensitive conductance is driving the spontaneous activity of DA neurons, rather than promoting a cooperation between different known ion channel species.

NALCN channels have been suggested to play a role in the pacemaking of DA neurons (Khaliq and Bean, 2010; Philippart and Khaliq, 2018). To test this hypothesis, we first performed extracellular recordings using $100 \mu \mathrm{M} \mathrm{Gd}^{3+}$, a known inhibitor of NALCN channels (Chua et al., 2020). This did not significantly alter the firing frequency of DA SNc neurons (Fig. S5A). As block by $\mathrm{Gd}^{3+}$ is not specific to NALCN channels (Boone et al., 2014), we tested the possibility of a direct effect of XG on NALCN. To this end, we heterologously expressed the NALCN complex (NALCN, UNC80, UNC79 and FAM155A (Lu et al., 2010, 2009; Xie et al., 2013; Yeh et al., 2008)) in Xenopus laevis oocytes and performed two-electrode voltage-clamp experiments. Yet even $3 \mathrm{mM} \mathrm{XG}$ only inhibited NALCN currents by $37 \pm 3.9 \%$ (at $-100 \mathrm{mV}, \mathrm{n}=6$ ), while $10 \mu \mathrm{M} \mathrm{Gd}^{3+}$ inhibited NALCN currents more potently $(74 \pm 9.3 \%$ inhibition at $-100 \mathrm{mV}, \mathrm{n}=6$ ) (Fig. S5B). Taken together, these experiments suggest that the effect of XG on pacemaking is unlikely to be due to blockade of NALCN channels.
A
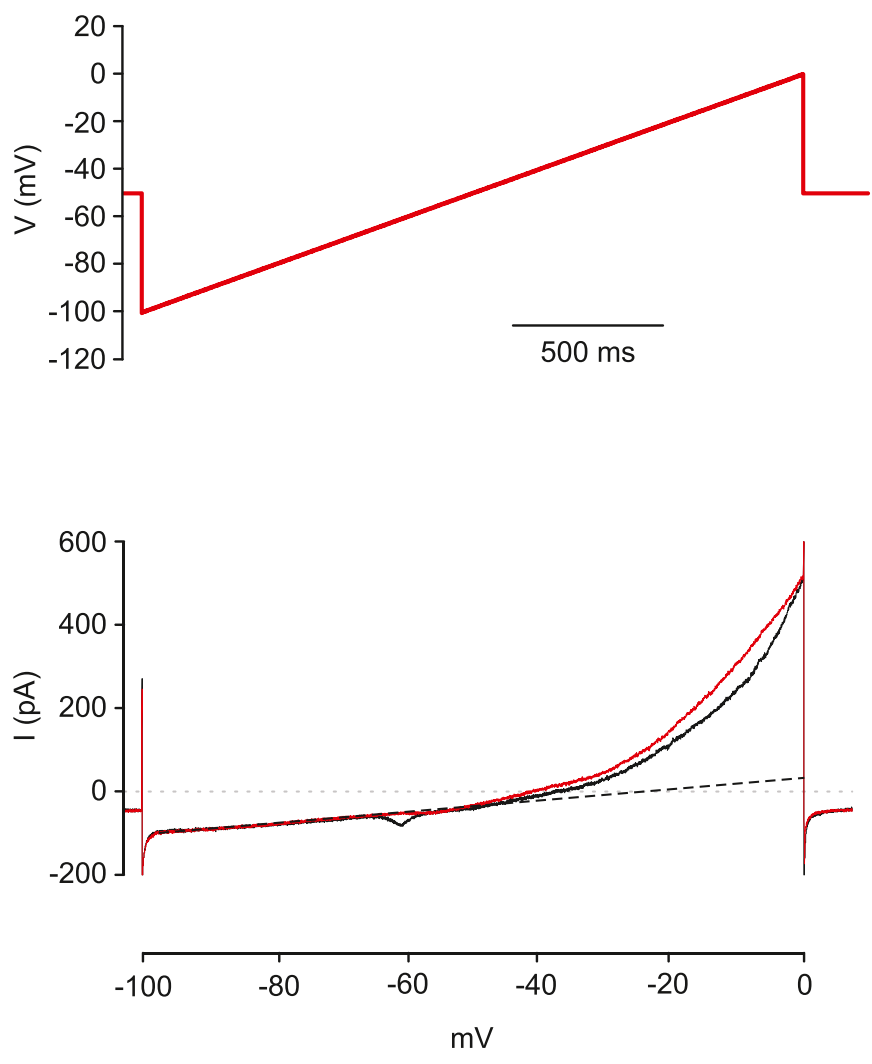

B

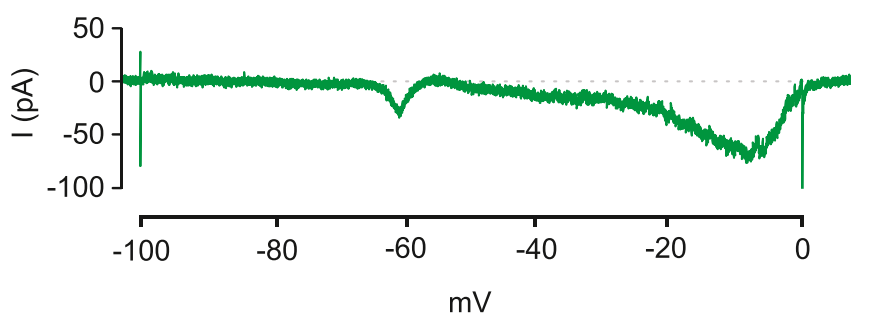

Fig. 6. Isolation of $I_{X G}$. A. Mean currents before (black) and after (red) application of $2 \mathrm{mM} \mathrm{XG}$ evoked in voltage-clamp by a ramp at a speed similar to the ISI $(25 \mathrm{mV} / \mathrm{s})$. In both conditions, 1 $\mu \mathrm{M}$ TTX, $20 \mathrm{mM}$ TEA, $200 \mu \mathrm{M} \mathrm{Cd}^{2+}$ and $2.5 \mathrm{mM}$ $\mathrm{Cs}^{+}$were applied to block respectively $\mathrm{Na}_{\mathrm{v}}$, most $\mathrm{K}^{+}, \mathrm{Ca}_{\mathrm{v}}$ and HCN channels. Dotted line corresponds to the extrapolated linear regression between $-98 \mathrm{mV}$ and $-70 \mathrm{mV}$. Its slope corresponds to an input resistance of $935 \mathrm{M} \Omega$. The inward current at $-60 \mathrm{mV}$ corresponds to a T-type $\mathrm{Ca}^{2+}$ current in control which is absent in the presence of XG, probably due to a rundown. This was observed only in one cell. B. Subtraction of the control trace by the trace in the presence of XG in A reveals $I_{X G}$ plotted as a function of voltage. Note that the current starts to operate at $-50 \mathrm{mV}$. (For interpretation of the references to color in this figure legend, the reader is referred to the Web version of this article.) 


\subsection{No clear evidence for $I_{\omega}$ in DA SNc neurons}

Our data so far suggests that XG inhibits an as yet unidentified conductance that is essential for pacemaking in DA SNc neurons. As XG blocks voltage-sensor-related $\omega$ pores but not the conventional $\alpha$ pores in mutant $\mathrm{Na}_{\mathrm{v}}$ channels (Sokolov et al., 2010), one possibility is that DA SNc neurons express a yet to be defined channel protein that provides a physiological XG-sensitive $\omega$ pore necessary for pacemaking. $\omega$ pores are often created by the replacement of an arginine in the fourth segments (S4) of the voltage sensor domain of mutant voltage-gated channels (Sokolov et al., 2007; Tombola et al., 2005). Depending on the location of the missing arginine, they generate either a small inward or outward current at hyperpolarized or depolarized potentials respectively (Held et al., 2016; Jiang et al., 2018). Therefore, we next aimed to obtain evidence for an involvement of $I_{\omega}$ and to identify a molecular candidate potentially carrying such a current in DA SNc neurons.

First, we used voltage-clamp recordings to isolate the XG-sensitive current $\left(I_{X G}\right)$ and examine its shape. Indeed, it had previously been shown that inward $I_{\omega}$ is prominent at negative $(-150$ to $-100 \mathrm{mV})$ potentials and becomes smaller at less negative $(-50 \mathrm{mV})$ voltages (Moreau et al., 2014; Sokolov et al., 2010). Therefore, we performed ramp recordings, from $-100 \mathrm{mV}$ to $0 \mathrm{mV}$. In these experiments, we applied $1 \mu \mathrm{M}$ TTX, $20 \mathrm{mM}$ TEA, $200 \mu \mathrm{M} \mathrm{Cd}^{2+}$ and $2.5 \mathrm{mM} \mathrm{Cs}^{+}$to block $\mathrm{Na}_{\mathrm{v}}$, most of $\mathrm{K}^{+}, \mathrm{Ca}_{\mathrm{v}}$ and $\mathrm{HCN}$ channels, respectively. Subtracting the current obtained in XG from control current yielded the XG-sensitive current. No current was observed at negative potentials $(n=5$, Fig. 6). However, we did observe a $I_{X G}$, from around $-55 \mathrm{mV}$ to less negative potentials (Fig. 6B). This voltage range coincides with the ISI (Khaliq and Bean, 2008), suggesting that this current could correspond to the pacemaker current. Thus, the shape of $I_{X G}$ is inconsistent with it being an inward $I_{\omega}$-like current.

Second, we addressed the possibility that the mRNA coding for an ion channel species could be edited physiologically in these cells by the type-2 adenosine deaminase acting on RNA (ADAR-2) enzyme. Such editing could convert an arginine of a S4 segment into a glycine. Indeed, ADAR-2 converts an adenosine into an inosine, which will be read as a guanosine. ADAR-2 is active in DA SNc neurons and has been shown to edit the IQ calmodulin-binding domain of $\mathrm{Ca}_{\mathrm{v}} 1.3$, thereby modulating the inactivation of this channel by $\mathrm{Ca}^{2+}$ (Huang et al., 2012). We sequenced cDNA from SNc neurons and cortical neurons (as a negative control) in the region coding for the S4 segments of $\mathrm{Na}_{\mathrm{v}} 1.1,1.2$ and 1.6 channels as there is ample evidence that pathological $\mathrm{Na}^{+}$channels do generate $I_{\omega}$ (Mason et al., 2019; Sokolov et al, 2005, 2007), and also sequenced the IQ calmodulin-binding domain of $\mathrm{Ca}_{\mathrm{v}} 1.3$ as a control. We found a small percentage of editing in some S4 domains, but this was observed in both SNc and cortex. On the other hand, we did confirm the heavy editing reported by Huang et al. demonstrating that our method was adequate (Table 2). The fact that there was no region-specific editing and the low percentage of editing indicate that $\omega$ pores are unlikely to be present in the tested channels. Taken together, our molecular and functional data are not in favor of the possibility that a typical gating pore current is the target of XG.

\subsection{XG blocks a current carried by $\mathrm{Na}^{+}$and $\mathrm{Cl}^{-}$}

Having identified the XG-sensitive current in DA SNc neurons in the relevant subthreshold range, our next aim was to define the permeant ions. To do so, while also attempting to mimic as closely as possible physiological conditions, we turned to a "pacemaker clamp" protocol (Puopolo et al., 2007). In this voltage-clamp approach, the waveform of a spontaneously firing DA neuron is imposed as the command potential and the resulting currents are recorded. We then ran the voltage-clamp protocol in a control solution and in $2 \mathrm{mM} \mathrm{XG}$ and subtracted the current traces. These experiments were performed in TTX, TEA and $\mathrm{Cd}^{2+}$. The internal control solution was K-gluconate-based. Consistent with our previous results, we observed a small inward $I_{X G}$ starting a few $\mathrm{mV}(-50$ to $-45 \mathrm{mV}$ ) below the threshold of the AP (Fig. 7A). In control conditions, the amplitude of this current was $-23.85 \pm 6.14 \mathrm{pA}(\mathrm{n}=6)$ just below the onset of the action potential $(-30 \mathrm{mV})$.

Next, we decreased the concentration of external $\mathrm{Ca}^{2+}$ ions from 2 to $0.1 \mathrm{mM}$. This procedure did not significantly change $I_{X G}$ amplitude $(-20.73 \pm 2.62 \mathrm{pA}, \mathrm{n}=6, \mathrm{p}=0.8028$ versus control, $\mathrm{F}(5,28)=3.945$, ANOVA-1; Fig. 7B,C,D), suggesting that $I_{X G}$ is not carried by $\mathrm{Ca}^{2+}$. We next substituted external $\mathrm{Na}^{+}$by the much larger cation choline. This made $I_{X G}$ strongly outward $\left(32.22 \pm 1.52 \mathrm{pA}\right.$ in choline $\mathrm{K}_{\mathrm{e}} \mathrm{Kglu}_{\text {in }}$ vs control $_{\mathrm{e}} \mathrm{Kglu}_{\text {in }}$ at $-30 \mathrm{mV}, \mathrm{n}=6, \mathrm{p}<0.0001$, ANOVA-1; Fig. 7B,C,D). These results indicate that $I_{X G}$ is partially carried by $\mathrm{Na}^{+}$, in addition to another ionic species that produces the outward component.

Table 2

Summary results from the sequencing of the various $\mathrm{S} 4$ segments of $\mathrm{Na}_{\mathrm{v}} 1.1,1.2$ and 1.6 channels in SNc and cortex $(\mathrm{n}=2)$. There is no evidence in favor of robust editing in these parts of the channels.

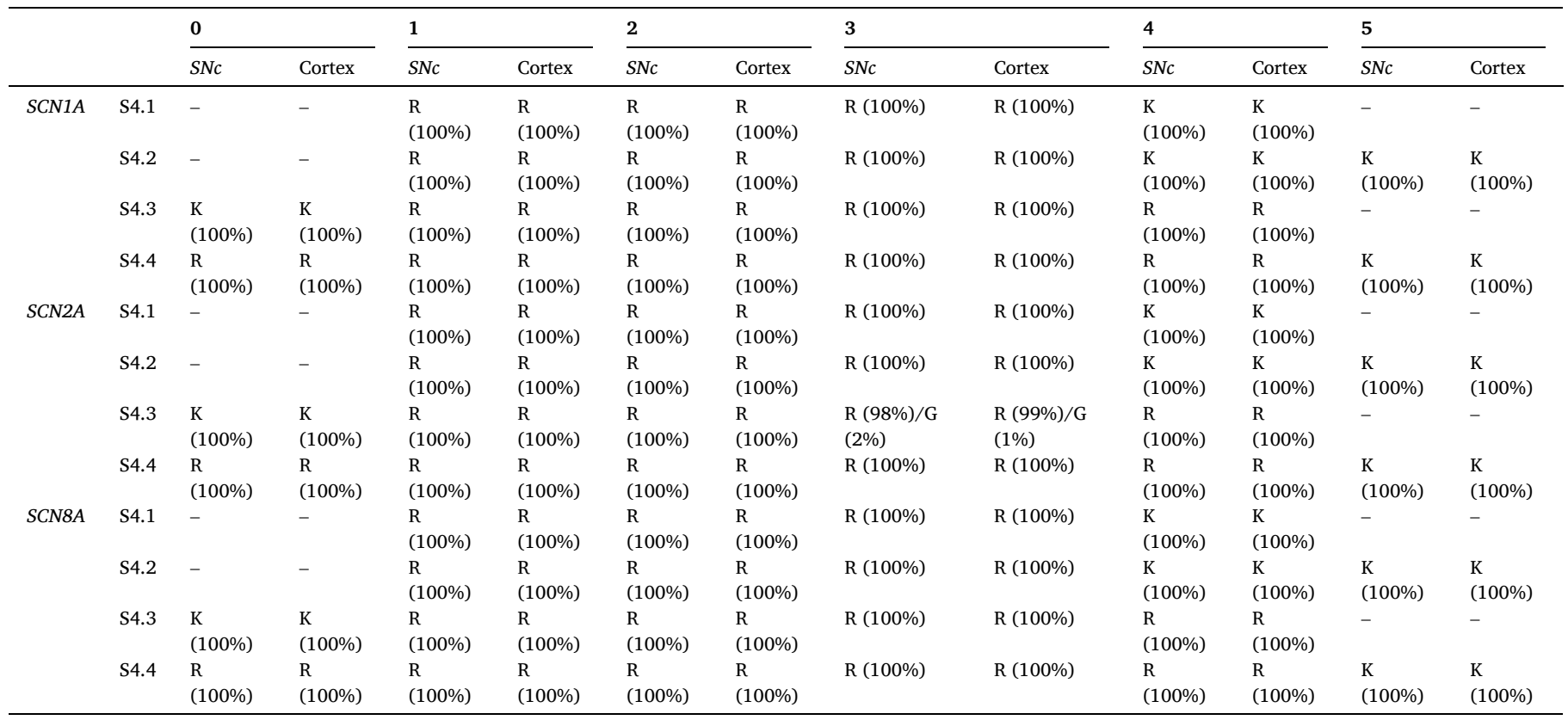


A
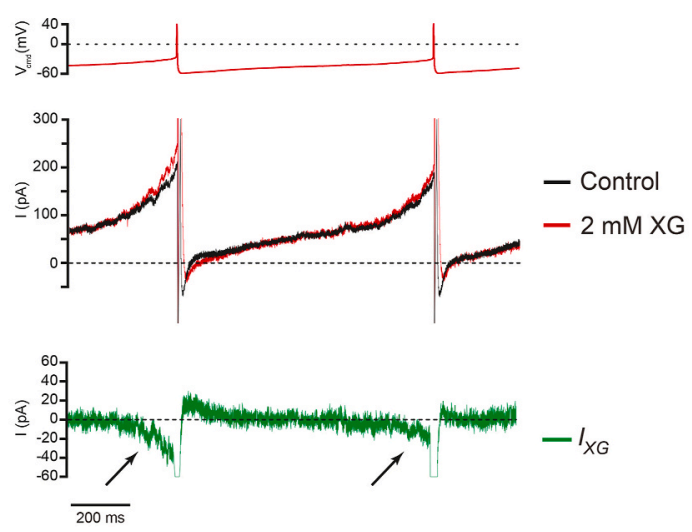

C

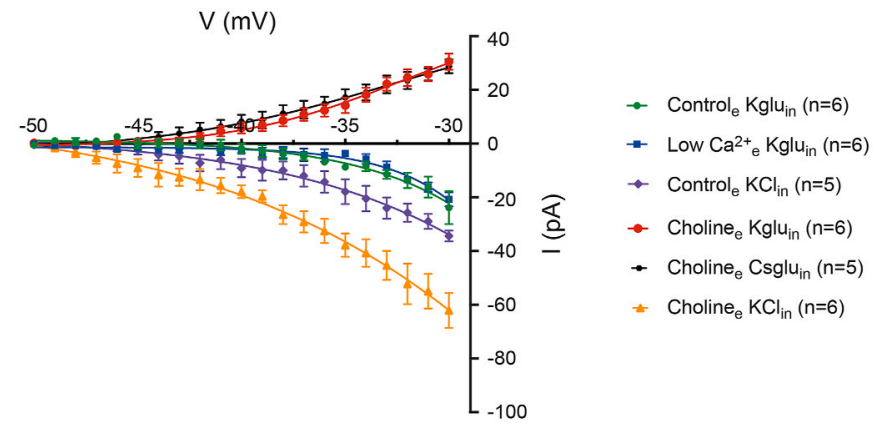

B
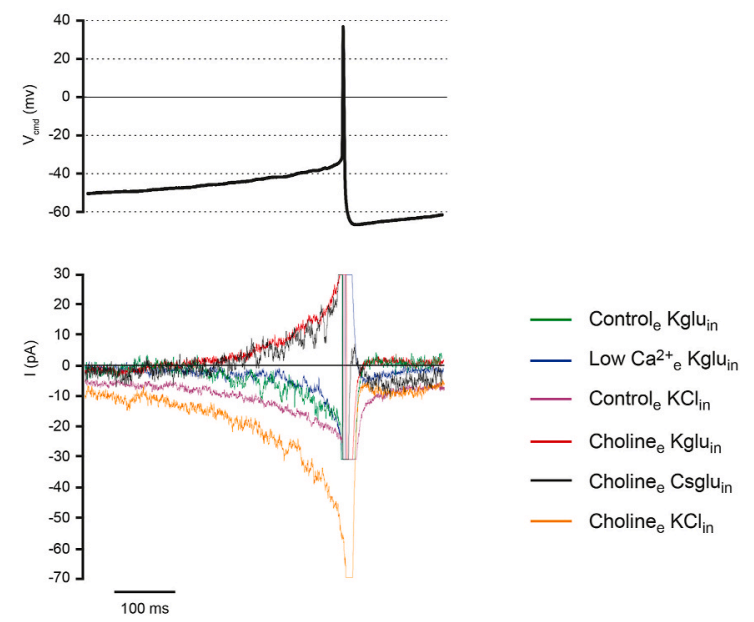

D

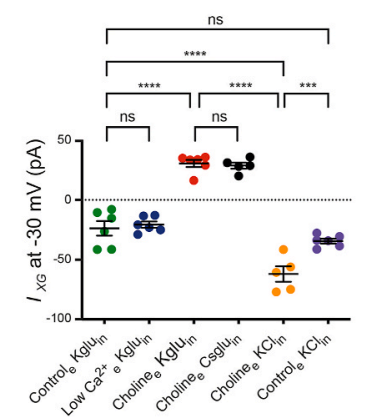

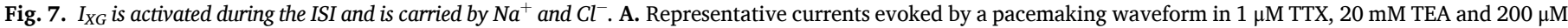

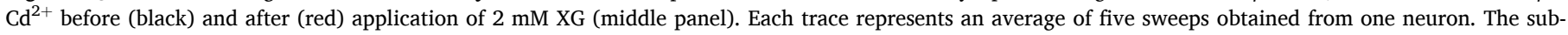

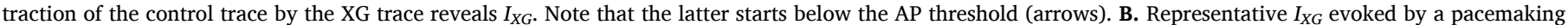

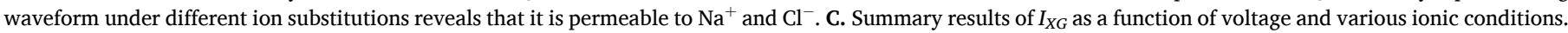

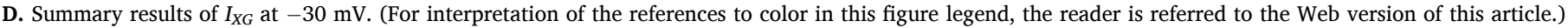

Given the experimental conditions, $\mathrm{K}^{+}$and $\mathrm{Cl}^{-}$were the most plausible candidates. First, we substituted internal $\mathrm{K}^{+}$by $\mathrm{Cs}^{+}$in the external choline condition, in order to isolate the outward component. This did not change the outward component of $I_{X G}\left(28.80 \pm 2.57 \mathrm{pA}\right.$ in choline $\mathrm{e}_{\mathrm{e}}$ Csglu $_{\text {in }}, \mathrm{n}=5$, vs choline $\mathrm{K}_{\mathrm{K}} \mathrm{glu}_{\text {in }}, \mathrm{p}=0.8028$, ANOVA-1; Fig. 7B,C,D), indicating that $\mathrm{K}^{+}$ions probably do not contribute to this current. Next, we increased the internal $\mathrm{Cl}^{-}$concentration from $25 \mathrm{mM}$ to $145 \mathrm{mM}$, resulting in a predicted shift of its reversal potential from $\sim-45 \mathrm{mV}$ to 0 $\mathrm{mV}$. Under these ionic conditions and in the presence of external choline, $I_{X G}$ was recorded as an inward current that was actually larger compared to the control condition $\left(-62.10 \pm 6.50 \mathrm{pA}\right.$ in choline $\mathrm{e}_{\mathrm{e}} \mathrm{KCl}_{\mathrm{in}}$, $\mathrm{n}=6$ vs control $_{\mathrm{e}} \mathrm{Kglu}_{\mathrm{in}}, \mathrm{p}<0.0001$, ANOVA-1; Fig. 7B,C,D). Taken together, these experiments indicated that $I_{X G}$ is carried by both $\mathrm{Cl}^{-}$and $\mathrm{Na}^{+}$ions.

Finally, we recorded $I_{X G}$ in external $\mathrm{Na}^{+}$and high internal $\mathrm{Cl}^{-}$. We hypothesized that, given that the two ionic species carry an inward current in these conditions, the global inward current would be larger than in the previous condition where only $\mathrm{Cl}^{-}$could carry it. However, surprisingly, we observed a significantly smaller inward current compared to the " $\mathrm{Cl}^{-}$only" condition $\left(-34.40 \pm 2.02 \mathrm{pA}\right.$ in control ${ }_{\mathrm{e}}$ $\mathrm{KCl}_{\text {in }}, \mathrm{n}=6$, vs choline $\mathrm{KCl}_{\text {in }}, \mathrm{p}=0.0002$, ANOVA-1, Fig. 7B,C,D). On the other hand, the current amplitude was not significantly different from that of the control condition ( control $_{e} \mathrm{KCl}_{\text {in }}$ vs control $_{\mathrm{e}} \mathrm{Kglu}_{\mathrm{in}}, \mathrm{p}=$ 0.1794, ANOVA-1). These results suggest that, in accordance with the Hill slope around $1, \mathrm{Na}^{+}$and $\mathrm{Cl}^{-}$ions flow through one pore.

\subsection{XG does not interact with the dopamine transporter}

Given the results of our ion substitution experiments (Fig. 7), we next turned to possible proteins that could sustain a low conductance permeable to both $\mathrm{Na}^{+}$and $\mathrm{Cl}^{-}$, and that would be expressed only in DA neurons. The dopamine transporter (DAT) was an obvious candidate since it is only expressed in DA neurons. In addition, while transporting DA, it takes up $\mathrm{Na}^{+}$and $\mathrm{Cl}^{-}$in a 2:1 ratio, generating a small inward current that is able to modulate DA neuron excitability (Carvelli et al., 2004; Ingram et al., 2002; Sonders et al., 1997). In order to test the possible involvement of the DAT in the XG-sensitive current, we took two distinct approaches.

First, we performed extracellular recordings in rat slices and applied $10 \mu \mathrm{M}$ GBR12909, a specific blocker of DA uptake. The compound produced no significant change in firing frequency when synaptic blockers (including sulpiride) were applied $(2.77 \pm 0.31 \mathrm{~Hz}$ in control vs $2.21 \pm 0.23 \mathrm{~Hz}$ in $10 \mu \mathrm{M}$ GBR12909, $\mathrm{n}=6$ for both conditions, $\mathrm{t}(5)=$ $1.516, \mathrm{p}=0.1900$, $t$-test; Fig. 8A). Additionally, superfusion of $2 \mathrm{mM} \mathrm{XG}$ inhibited the firing of DA neurons to the same extent as in control conditions (from $2.28 \pm 0.18 \mathrm{~Hz}$ in $10 \mu \mathrm{M}$ GBR12909 to $0.01 \pm 0.01 \mathrm{~Hz}$ in $2 \mathrm{mM} \mathrm{XG}, \mathrm{n}=6$ for both conditions, $\mathrm{p}=0.03$, Wilcoxon test; Fig. $8 \mathrm{~B}$ ). These observations suggest that uptake of DA is not generating the spontaneous firing and that DAT is probably not the target of XG.

Second, in order to confirm those results, we performed extracellular recordings on wild type and $\mathrm{DAT}^{-/-}$mice. DA neurons from $\mathrm{DAT}^{-/-}$mice were spontaneously active (Fig. $8 \mathrm{C}$ ). Their firing rate was similar to the 
A

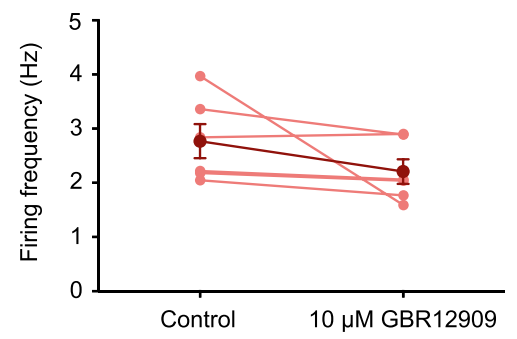

B

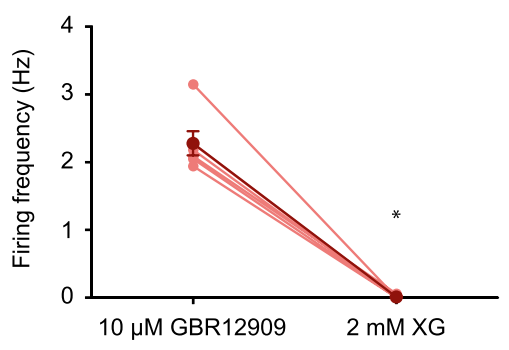

$\mathrm{D}$

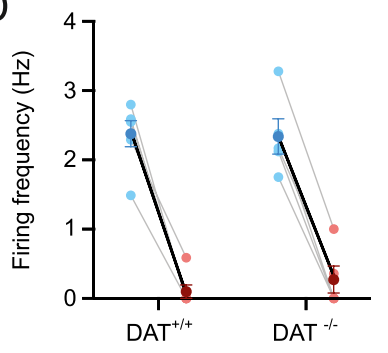

- Control

- $2 \mathrm{mM} \times \mathrm{G}$

Genetic variant : ns

Exposition : ****

Interaction : ns
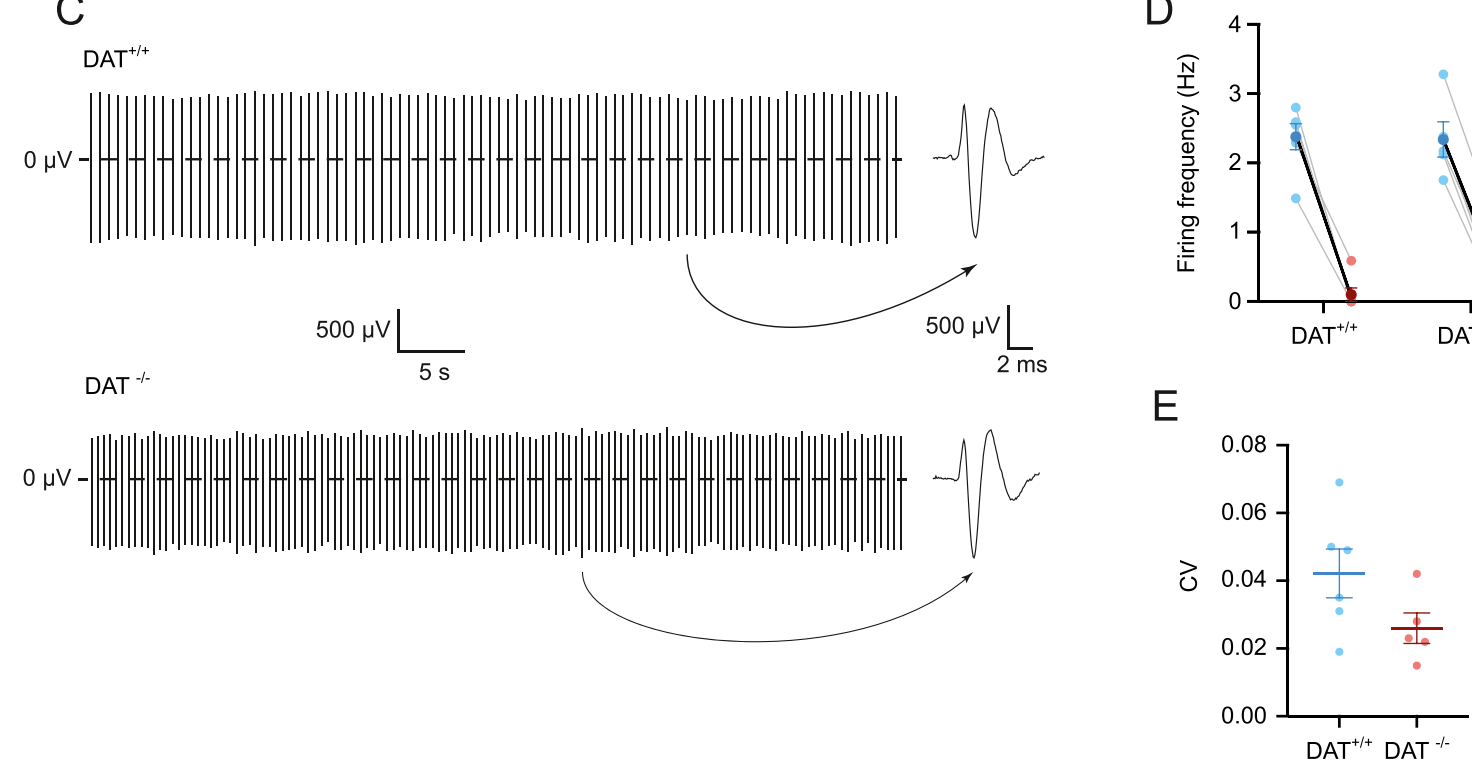

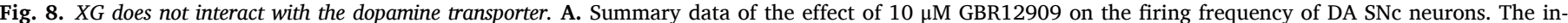

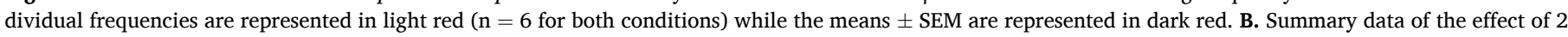

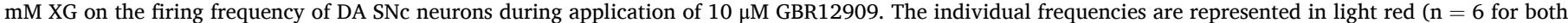

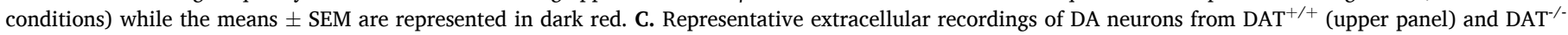

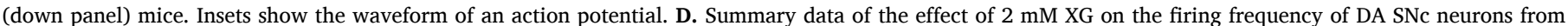

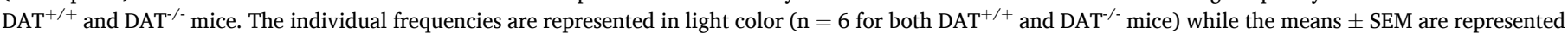

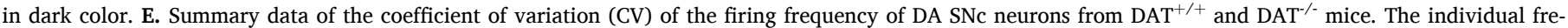

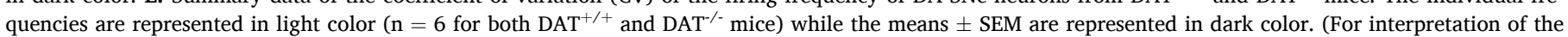
references to color in this figure legend, the reader is referred to the Web version of this article.)

one of WT neurons $\left(2.38 \pm 0.19 \mathrm{~Hz}\right.$ for $\mathrm{DAT}^{+/+}, \mathrm{n}=6 \mathrm{vs} 2.34 \pm 0.26 \mathrm{~Hz}$ for $\mathrm{DAT}^{-/-}, \mathrm{n}=5, \mathrm{~F}(1,9)=0.08610, \mathrm{p}=0.7759$, ANOVA-2; Fig. $8 \mathrm{c}, \mathrm{d}$ ), as was their regularity (coefficient of variation of the ISI was $0.042 \pm 0.007$ for $\mathrm{DAT}^{+/+}, \mathrm{n}=6$ vs $0.026 \pm 0.005$ for $\mathrm{DAT}^{-/-}, \mathrm{n}=5, \mathrm{t}(9)=1.815, \mathrm{p}=$ $0.1, t$-test; Fig. 8E). In addition, XG inhibited the firing of DA neurons from the two genotypes to a similar extent $(\mathrm{F}(1,9)=0.6257, \mathrm{p}=0.4493$, ANOVA-2; Fig. 8D). Taken together, these two types of experiments demonstrate that XG does not interact with the DAT and that the latter is not responsible for the spontaneous activity of DA SNc neurons.

\section{Discussion}

We have tested the hypothesis that a compound previously reported to be a gating pore blocker, $\mathrm{XG}$, is able to inhibit the spontaneous slow pacemaking of DA SNc neurons. Our results show that this is indeed the case in both rat and mouse DA neurons and in slices taken from both juvenile and adult animals. The $\mathrm{IC}_{50}$ of the compound is in the high micromolar range and consistent with the pharmacology of $I_{\omega}$ (Sokolov et al., 2010). Using two different salts of XG allowed us to establish that it is the xylylguanidinium moiety that is responsible for the observed inhibition. Moreover, we found that XG inhibits pacemaking of DA neurons without hyperpolarizing them and without increasing their whole-cell conductance (contrary to what a $\mathrm{K}^{+}$channel opener would do). Finally, we found that XG displays a reasonable degree of specificity, since fast GABAergic pacemaker neurons of the $\mathrm{SNr}$ and slow pacemaker neurons of the LC were unaffected by the drug. Therefore, we believe that we have found the first specific inhibitor of the spontaneous activity of DA neurons. In addition, XG inhibits pacemaking of DA neurons, but does not affect their bursting behavior. To our knowledge, this is the first compound that is able to do so. In addition, the $I_{X G^{-}}$ sensitive current has a shape that is fundamentally different from what was previously reported for inward gating pore currents (Sokolov et al., 2010). An effect of XG via inhibition of NALCN channels is also unlikely. Intriguingly, we demonstrated that the $I_{X G^{-}}$-sensitive current is carried by both $\mathrm{Na}^{+}$and $\mathrm{Cl}^{-}$. However, although the DAT transports $\mathrm{Na}^{+}$and $\mathrm{Cl}^{-}$ during dopamine uptake, we could rule out that this protein sustains slow pacemaking in DA neurons.

Mesencephalic DA neurons constitute a heterogeneous population in terms of electrophysiological and molecular properties. The electrophysiological characteristics of mesencephalic DA neurons, including AP duration and the density of $\mathrm{I}_{\mathrm{A}}$ and $\mathrm{I}_{\mathrm{h}}$, vary along a medio-lateral axis going from mesocortical projections (medial) to nigrostriatal projections (lateral) (Amendola et al., 2012; Lammel et al., 2008; Margolis et al., 2008; Neuhoff et al., 2002; Tarfa et al., 2017). In addition, 
mesoprefrontal VTA DA neurons in mice (Lammel et al., 2008) and amygdala-projecting VTA DA neurons in rats (Margolis et al., 2008) display unique properties, such as lack of somato-dendritic D2 receptors and high-frequency pacemaking. As far as the slow pacemaking activity is concerned, various types of voltage-dependent channels have been suggested or shown to contribute to it, including several types of $\mathrm{Ca}_{\mathrm{v}}$ channels, e.g. L-type channels in some cells and $\mathrm{P} / \mathrm{Q}$ type channels in other cells (Puopolo et al., 2007), as well as HCN channels (Neuhoff et al., 2002; Seutin et al., 2001). In addition, the ionic nature of the channels operating during the ISI differs between VTA and SNc DA neurons (Khaliq and Bean, 2010; Puopolo et al., 2007), even though the spontaneous activity is remarkably similar in DA neurons of both regions. In this study, we found a complete or near complete inhibition of firing with $2 \mathrm{mM} \mathrm{XG}$ in all neurons that we studied (fast mesoprefrontal pacemakers were not recorded). We suggest that the XG-sensitive conductance provides the depolarizing drive in all slow DA pacemakers. Thus, these neurons, regardless of their location within the midbrain, would be endowed with a robust common pacemaking mechanism, on top of which additional conductances would be present in a region-specific manner. An obvious alternative interpretation of our results is that XG somehow inhibits or activates several ion channel species. We do not favor this hypothesis for the following reasons: 1) XG inhibited the firing of all DA neurons, whatever their location in the midbrain, in a very consistent manner, despite the heterogeneity of their properties (see above). It is very unlikely that a same drug would inhibit with the same potency a population of neurons having a variable ion channel expression profile. 2) XG did not modulate the biophysical properties of $I_{A}$ or $I_{h}$. 3) Blockers of individual $\mathrm{Ca}_{V}$ currents and also mixtures of them do not affect pacemaking of SNc DA neurons (de Vrind et al., 2016).

XG has only been described so far as a blocker of $I_{\omega}$ (Sokolov et al., 2010). Regarding the effect of $I_{\omega}$ on cell excitability, it has been shown that $\mathrm{R} 222 \mathrm{~W}$ in $\mathrm{hNa}_{\mathrm{v}} 1.4$ channels shifts the resting potential of muscle fibers to more depolarized state, facilitating the generation of APs (Bayless-Edwards et al., 2018). The amplitude of APs is also decreased as the sustained inward current reduces $\mathrm{Na}_{\mathrm{v}}$ channel availability (this did not seem to be the case in DA neurons). In the brain, R853Q $\mathrm{hNa}_{\mathrm{v}} 1.2$ channels have been shown to generate a $\mathrm{K}^{+}$-selective inward current linked to epilepsy (Mason et al., 2019; Sokolov et al., 2005). Our data show no evidence for an $I_{\omega}$, as we did not observe XG-sensitive inward currents at hyperpolarized potentials (Fig. 6B) and the sequencing of $\mathrm{Na}_{\mathrm{v}}$ channels S4 did not show any R/X variant (Table 2). However, we cannot exclude that editing occurs in DA neurons in channels that were not investigated in our study, as $\omega$ pores were also observed previously in Shaker $\mathrm{K}^{+}$channels (Starace and Bezanilla, 2004; Tombola et al., 2005). Note that a combined permeability to cations and anions has been previously demonstrated for $I_{\omega}$ (Khalili-Araghi et al., 2012). Therefore, our results do not formally exclude that a gating pore current underlies pacemaking in DA neurons. Other possibilities exist. For example, it has been shown that the biophysical properties of voltage-gated proton channels are similar to the ones of $\omega$ pores (Hong et al., 2013). Since they are blocked by guanidinium derivatives, the structures of which are very similar to the one of XG, it is possible that such channels are the target of XG. A previous study identified 21 family members related to voltage-gated proton channels and of unknown function that could be candidate targets of XG (Musset et al., 2011).

We observed a partial inhibition of NALCN channels by high concentrations of XG (Fig. S3B). However, we could not attribute the inhibition of pacemaking by XG to an interaction with NALCN channels, as $\mathrm{Gd}^{3+}$, an unselective but potent blocker of these channels, did not change the firing frequency (Fig. S3a). Monitoring the effect of XG on DA neurons from $\mathrm{NALCN}^{-/}$animals will help to address this question further, as $\sim 30 \%$ of DA neurons in these animals still fire spontaneously (Philippart and Khaliq, 2018).

Even though we did not identify the molecular target of XG, we characterized its ion permeability and found that both $\mathrm{Na}^{+}$and $\mathrm{Cl}^{-}$ permeate, likely through the same pore. This mechanism may be critical to ensure the temporal stability of pacemaking. Thus, any depolarizing event will increase the ratio of $\mathrm{Cl}^{-}$versus $\mathrm{Na}^{+}$influx and the converse will be true for a hyperpolarizing event. This is what we would expect from a pacemaker current in order to sustain a stable spontaneous activity. In light of our results, we speculate that $I_{X G}$ might correspond to the small inward current in the ISI described by others (Khaliq and Bean, 2008). We expect that a full characterization of $I_{X G}$, when identified, can be used to verify the mechanism we propose in a computational model of DA neuron pacemaking.

\section{Conclusion}

Overall, we have discovered that XG is the first specific inhibitor of pacemaking in DA neurons. The effect of XG is specific both versus bursting in these neurons and versus pacemaking of other neurons. We favor the possibility that XG inhibits a specific conductance that enables oscillatory phenomena in DA neurons. Despite the fact that this compound was originally described as a gating pore current blocker, we were unable to confirm the involvement of such a conductance, although we could not disprove it entirely either. Our work represents a first step toward the full characterization of the pacemaker mechanism in these neurons.

\section{Data availability statement}

The data supporting this study are available from the corresponding author upon reasonable request.

\section{Jehasse et al. credit author statement}

Kevin Jehasse : conceptualization, investigation, writing original draft. Laurent Massotte : investigation. Sebastian Hartmann : investigation. Romain Vitello : resources. Sofian Ringlet : investigation. Marie Vitello : investigation. Han Chow Chua : investigation. Stephan A Pless : conceptualization, writing - review and editing. Dominique Engel : methodology. Jean-François Liégeois : resources. Bernard Lakaye : methodology, conceptualization. Jochen Roeper : conceptualization, writing - review and editing. Vincent Seutin : conceptualization, writing - review and editing, funding acquisition

\section{Declaration of competing interest}

The authors declare no conflicts of interest with respect to the research, authorship, or publication of this article.

\section{Acknowledgements}

We thank all the members from the laboratory of Neurophysiology for the helpful discussions and their suggestions. We are also grateful to the GIGA-Genomics platform for the sequencing of mRNA. This work was supported by grants from the "Fonds National de la Recherche Scientifique" (FNRS, Belgium) (J.0148.19 to VS), from the "Fondation Léon Fredericq" (Belgium) (FHULF-D.MESGCAN.01-05 and "prix de l'espoir" to KJ). JFL is a Research Director of the F.R.S.-FNRS. DE and BL are Research Associates of the F.R.S.-FNRS. The salaries of KJ, RV and SR are paid by the "Fonds de la Recherche dans l'Industrie et l'Agriculture" (FRIA).

\section{Appendix ASupplementary data}

Supplementary data to this article can be found online at https://doi. org/10.1016/j.neuropharm.2021.108722. 


\section{References}

Albin, R.L., Young, A.B., Penney, J.B., 1989. The functional anatomy of basal ganglia disorders. Trends Neurosci. 12, 366-375. https://doi.org/10.1016/0166-2236(89) 90074-X.

Amendola, J., Woodhouse, A., Martin-Eauclaire, M.F., Goaillard, J.M., 2012. Ca 2+/ cAMP-sensitive covariation of I A and I $\mathrm{H}$ voltage dependences tunes rebound firing in dopaminergic neurons. J. Neurosci. 32, 2166-2181. https://doi.org/10.1523/ JNEUROSCI.5297-11.2012.

Bayless-Edwards, L., Winston, V., Lehmann-Horn, F., Arinze, P., Groome, J.R., JurkatRott, K., 2018. NaV1.4 DI-S4 periodic paralysis mutation R222W enhances inactivation and promotes leak current to attenuate action potentials and depolarize muscle fibers. Sci. Rep. 8, 1-13. https://doi.org/10.1038/s41598-018-28594-5.

Blythe, S.N., Atherton, J.F., Bevan, M.D., 2007. Synaptic activation of dendritic AMPA and NMDA receptors generates transient high-frequency firing in substantia nigra dopamine neurons in vitro. J. Neurophysiol. 97, 2837-2850. https://doi.org/ 10.1152/jn.01157.2006.

Boone, A.N., Senatore, A., Chemin, J., Monteil, A., Spafford, J.D., 2014. Gd3+ and calcium sensitive, sodium leak currents are features of weak membrane-glass seals in patch clamp recordings. PloS One 9. https://doi.org/10.1371/journal. pone.0098808.

Carvelli, L., Mcdonald, P.W., Blakely, R.D., Defelice, L.J., 2004. Dopamine transporters depolarize neurons by a channel mechanism. Proc. Natl. Acad. Sci. Unit. States Am. 101, 16046-16051. https://doi.org/10.1073/pnas.0403299101.

Chan, C.S., Guzman, J.N., Ilijic, E., Mercer, J.N., Rick, C., Tkatch, T., Meredith, G.E., Surmeier, D.J., 2007. 'Rejuvenation' protects neurons in mouse models of Parkinson's disease. Nature 447, 1081-1086. https://doi.org/10.1038/ nature05865.

Chua, H.C., Wulf, M., Weidling, C., Rasmussen, L.P., Pless, S.A., 2020. The NALCN channel complex is voltage sensitive and directly modulated by extracellular calcium. Sci. Adv. 6 https://doi.org/10.1126/sciadv.aaz3154.

de Vrind, V., Scuvée-Moreau, J., Drion, G., Hmaied, C., Philippart, F., Engel, D., Seutin, V., 2016. Interactions between calcium channels and SK channels in midbrain dopamine neurons and their impact on pacemaker regularity: contrasting roles of N- and l-type channels. Eur. J. Pharmacol. 788, 274-279. https://doi.org/ 10.1016/j.ejphar.2016.06.046.

Destreel, G., Seutin, V., Engel, D., 2019. Subsaturation of the N-methyl-D-aspartate receptor glycine site allows the regulation of bursting activity in juvenile rat nigral dopamine neurons. Eur. J. Neurosci. 50, 3454-3471. https://doi.org/10.1111/ ejn.14491.

Drion, G., Massotte, L., Sepulchre, R., Seutin, V., 2011. How modeling can reconcile apparently discrepant experimental results: the case of pacemaking in dopaminergic neurons. PLoS Comput. Biol. 7, e1002050 https://doi.org/10.1371/journal. pcbi.1002050.

Dufour, M.A., Woodhouse, A., Amendola, J., Goaillard, J.M., 2014. Non-linear developmental trajectory of electrical phenotype in rat substantia nigra pars compacta dopaminergic neurons. Elife 3. https://doi.org/10.7554/eLife.04059.

Evans, R.C., Zhu, M., Khaliq, Z.M., 2017. Dopamine inhibition differentially controls excitability of substantia nigra dopamine neuron subpopulations through T-type calcium channels. J. Neurosci. 37, 3704-3720. https://doi.org/10.1523/ JNEUROSCI.0117-17.2017.

Farassat, N., Costa, Kauê Machado, Stovanovic, S., Albert, S., Kovacheva, L., Shin, J., Egger, R., Somayaji, M., Duvarci, S., Schneider, G., Roeper, J., 2019. In vivo functional diversity of midbrain dopamine neurons within identified axonal projections. Elife 8. https://doi.org/10.7554/elife.48408.

Galtieri, D.J., Estep, C.M., Wokosin, D.L., Traynelis, S., Surmeier, D.J., 2017. Pedunculopontine glutamatergic neurons control spike patterning in substantia nigra dopaminergic neurons. Elife 6. https://doi.org/10.7554/eLife.30352.

Giros, B., Jaber, M., Jones, S.R., Wightman, R.M., Caron, M.G., 1996. Hyperlocomotion and indifference to cocaine and amphetamine in mice lacking the dopamine transporter. Nature 379, 606-612. https://doi.org/10.1038/379606a0.

Gonon, F., Bloch, B., 1998. Kinetics and geometry of the excitatory dopaminergic transmission in the rat striatum in vivo. Adv. Pharmacol. 42, 140-144. https://doi. org/10.1016/s1054-3589(08)60715-2.

Grace, A.A., Bunney, B.S., 1984. The control of firing pattern in nigral dopamin neurons: burst firing. J. Neurosci. 4, 2877-2890. https://doi.org/10.1523/ jneurosci.04-11-02877.1984.

Guzman, J.N., Sánchez-Padilla, J., Chan, C.S., Surmeier, D.J., 2009. Robust pacemaking in substantia nigra dopaminergic neurons. J. Neurosci. 29, 11011-11019. https:// doi.org/10.1523/JNEUROSCI.2519-09.2009.

Held, K., Voets, T., Vriens, J., 2016. Signature and pathophysiology of non-canonical pores in voltage-dependent cation channels. Rev. Physiol. Biochem. Pharmacol. 170, 67-99. https://doi.org/10.1007/112 2015 5003.

Hong, L., Pathak, M.M., Kim, I.H., Ta, D., Tombola, F., 2013. Voltage-sensing domain of voltage-gated proton channel Hv1 shares mechanism of block with pore domains. Neuron 77, 274-287. https://doi.org/10.1016/j.neuron.2012.11.013.

Huang, H., Tan, B.Z., Shen, Y., Tao, J., Jiang, F., Sung, Y.Y., Ng, C.K., Raida, M., Köhr, G., Higuchi, M., Fatemi-Shariatpanahi, H., Harden, B., Yue, D.T., Soong, T.W., 2012. RNA editing of the IQ domain in Cav1.3 channels modulates their Ca2+-dependent inactivation. Neuron 73, 304-316. https://doi.org/10.1016/j.neuron. 2011.11.022.

Ingram, S.L., Prasad, B.M., Amara, S.G., 2002. Dopamine transporter-mediated conductances increase excitability of midbrain dopamine neurons. Nat. Neurosci. 5 971-978. https://doi.org/10.1038/nn920.

Jiang, D., Gamal el-Din, Tamer M., Ing, C., Lu, P., Pomès, R., Zheng, N., Catterall, W.A., 2018. Structural basis for gating pore current in periodic paralysis. Nature 557, 590-594. https://doi.org/10.1038/s41586-018-0120-4.
Johnson, S.W., Seutin, V., North, R.A., 1992. Burst firing in dopamine neurons induced by N-methyl-D-aspartate: role of electrogenic sodium pump. Science 258, 665-667. https://doi.org/10.1126/science.1329209.

Khalili-Araghi, F., Tajkhorshid, E., Roux, B., Schulten, K., 2012. Molecular dynamics investigation of the $\omega$-current in the Kv1.2 voltage sensor domains. Biophys. J. 102, 258-267. https://doi.org/10.1016/j.bpj.2011.10.057.

Khaliq, Z.M., Bean, B.P., 2010. Pacemaking in dopaminergic ventral tegmental area neurons: depolarizing drive from background and voltage-dependent sodium conductances. J. Neurosci. 30, 7401-7413. https://doi.org/10.1523/jneurosci.014310.2010 .

Khaliq, Z.M., Bean, B.P., 2008. Dynamic, nonlinear feedback regulation of slow pacemaking by A-type potassium current in ventral tegmental area neurons. J. Neurosci. 28, 10905-10917. https://doi.org/10.1523/jneurosci.2237-08.2008.

Lammel, S., Hetzel, A., Häckel, O., Jones, I., Liss, B., Roeper, J., 2008. Unique properties of mesoprefrontal neurons within a dual mesocorticolimbic dopamine System. Neuron 57, 760-773. https://doi.org/10.1016/j.neuron.2008.01.022.

Liss, B., Roeper, J., 2008. Individual dopamine midbrain neurons: functional diversity and flexibility in health and disease. Brain Res. Rev. 58, 314-321. https://doi.org/ 10.1016/j.brainresrev.2007.10.004.

Lu, B., Su, Y., Das, S., Wang, H., Wang, Y., Liu, J., Ren, D., 2009. Peptide neurotransmitters activate a cation channel complex of NALCN and UNC-80. Nature 457, 741-744. https://doi.org/10.1038/nature07579.

Lu, B., Zhang, Q., Wang, H., Wang, Y., Nakayama, M., Ren, D., 2010. Extracellular calcium controls background current and neuronal excitability via an UNC79UNC80-NALCN cation channel complex. Neuron 68, 488-499. https://doi.org/ 10.1016/j.neuron.2010.09.014.

Margolis, E.B., Mitchell, J.M., Ishikawa, J., Hjelmstad, G.O., Fields, H.L., 2008. Midbrain dopamine neurons: projection target determines action potential duration and dopamine D2 receptor inhibition. J. Neurosci. 28, 8908-8913. https://doi.org/ 10.1523/JNEUROSCI.1526-08.2008.

Mason, E.R., Wu, F., Patel, R.R., Xiao, Y., Cannon, S.C., Cummins, T.R., 2019. Resurgent and gating pore currents induced by De Novo SCN2A epilepsy mutations. eNeuro 6, 1-17. https://doi.org/10.1523/ENEURO.0141-19.2019.

Mercuri, N.B., Bond, A., Calabresi, P., Stratta, F., Stefani, A., Bernardi, G., 1994. Effects of dihydropyridine calcium antagonists on rat midbrain dopaminergic neurones. $\mathrm{Br}$. J. Pharmacol. 113, 831-838. https://doi.org/10.1111/j.1476-5381.1994.tb17068.x.

Meyrath, M., Szpakowska, M., Zeiner, J., Massotte, L., Merz, M.P., Benkel, T., Simon, K., Ohnmacht, J., Turner, J.D., Krüger, R., Seutin, V., Ollert, M., Kostenis, E., Chevigné, A., 2020. The atypical chemokine receptor ACKR3/CXCR7 is a broadspectrum scavenger for opioid peptides. Nat. Commun. 11, 1-16. https://doi.org/ 10.1038/s41467-020-16664-0.

Moreau, A., Gosselin-Badaroudine, P., Chahine, M., 2014. Molecular biology and biophysical properties of ion channel gating pores. Q. Rev. Biophys. 47, 364-388. https://doi.org/10.1017/S0033583514000109.

Musset, B., Smith, S.M.E., Rajan, S., Morgan, D., Cherny, V.V., Decoursey, T.E., 2011. Aspartate 112 is the selectivity filter of the human voltage-gated proton channel. Nature 480, 273-277. https://doi.org/10.1038/nature10557.

Nedergaard, S., Flatman, J.A., Engberg, I., 1993. Nifedipine- and omega-conotoxinsensitive $\mathrm{Ca} 2+$ conductances in Guinea-pig substantia nigra pars compacta neurones. J. Physiol. 466, 727-747. https://doi.org/10.1113/jphysiol.1993. sp019742.

Neuhoff, H., Neu, A., Liss, B., Roeper, J., 2002. I(h) channels contribute to the different functional properties of identified dopaminergic subpopulations in the midbrain. J. Neurosci. 22, 1290-1302. https://doi.org/10.1523/JNEUROSCI.22-04. 01290.2002

Nieoullon, A., 2002. Dopamine and the regulation of cognition and attention. Prog. Neurobiol. 67, 53-83. https://doi.org/10.1016/S0301-0082(02)00011-4.

O'Leary, T., Williams, A.H., Franci, A., Marder, E., 2014. Cell types, network homeostasis, and pathological compensation from a biologically plausible ion channel expression model. Neuron 82, 809-821. https://doi.org/10.1016/j. neuron.2014.04.002.

Philippart, F., Destreel, G., Merino-Sepúlveda, P., Henny, P., Engel, D., Seutin, V., 2016. Differential somatic $\mathrm{Ca} 2+$ channel profile in midbrain dopaminergic neurons. J. Neurosci. 36, 7234-7245. https://doi.org/10.1523/JNEUROSCI.0459-16.2016.

Philippart, F., Khaliq, Z.M., 2018. Gi/o protein-coupled receptors in dopamine neurons inhibit the sodium leak channel NALCN. Elife 7. https://doi.org/10.7554/ eLife.40984.

Poulin, J.-F., Zou, J., , Drouin-Ouellet, J., Kim, K.-Y.A., Cicchetti, F., Awatramani, R.B., 2014. Defining midbrain dopaminergic neuron diversity by single-cell gene expression profiling. Cell Rep. 9, 930-943. https://doi.org/10.1016/j. celrep.2014.10.008.

Puopolo, M., Raviola, E., Bean, B.P., 2007. Roles of subthreshold calcium current and sodium current in spontaneous firing of mouse midbrain dopamine neurons. J. Neurosci. 27, 645-656. https://doi.org/10.1523/JNEUROSCI.4341-06.2007.

Richards, C.D., Shiroyama, T., Kitai, S.T., 1997. Electrophysiological and immunocytochemical characterization of GABA and dopamine neurons in the substantia nigra of the rat. Neuroscience 80, 545-557. https://doi.org/10.1016/ S0306-4522(97)00093-6.

Schultz, W., 2007. Multiple dopamine functions at different time courses. Annu. Rev. Neurosci. 30, 259-288. https://doi.org/10.1146/annurev.neuro.28.061604.135722.

Seutin, V., Engel, D., 2010. Differences in Na+ conductance density and $\mathrm{Na}+$ channel functional properties between dopamine and GABA neurons of the rat substantia nigra. J. Neurophysiol. 103, 3099-3114. https://doi.org/10.1152/jn.00513.2009.

Seutin, V., Massotte, L., Renette, M.F., Dresse, A., 2001. Evidence for a modulatory role of Ih on the firing of a subgroup of midbrain dopamine neurons. Neuroreport 12, 255-258. https://doi.org/10.1097/00001756-200102120-00015. 
Seutin, V., Verbanck, P., Massotte, L., Dresse, A., 1989. Galanin decreases the activity of locus coeruleus neurons in vitro. Eur. J. Pharmacol. 164, 373-376. https://doi.org/ 10.1016/0014-2999(89)90481-0.

Sokolov, S., Scheuer, T., Catterall, W.A., 2010. Ion permeation and block of the gating pore in the voltage sensor of NaV1.4 channels with hypokalemic periodic paralysis mutations. J. Gen. Physiol. 136, 225-236. https://doi.org/10.1085/jgp.201010414.

Sokolov, S., Scheuer, T., Catterall, W.A., 2007. Gating pore current in an inherited ion channelopathy. Nature 446, 76-78. https://doi.org/10.1038/nature05598.

Sokolov, S., Scheuer, T., Catterall, W.A., 2005. Ion permeation through a voltagesensitive gating pore in brain sodium channels having voltage sensor mutations. Neuron 47, 183-189. https://doi.org/10.1016/J.NEURON.2005.06.012.

Sonders, M.S., Zhu, S.J., Zahniser, N.R., Kavanaugh, M.P., Amara, S.G., 1997. Multiple ionic conductances of the human dopamine transporter: the actions of dopamine and psychostimulants. J. Neurosci. 17, 960-974. https://doi.org/10.1523/ JNEUROSCI.17-03-00960.1997.

Starace, D.M., Bezanilla, F., 2004. A proton pore in a potassium channel voltage sensor reveals a focused electric field. Nature 427, 548-553. https://doi.org/10.1038/ nature 02270

Sun, Y., Zhang, X.H., Selvaraj, S., Sukumaran, P., Lei, S., Birnbaumer, L., Brij, X. Singh, B., 2017. Inhibition of L-type Ca 2 channels by TRPC1-STIM1 complex is essential for the protection of dopaminergic neurons. J. Neurosci. 37, 3364-3377. https://doi.org/10.1523/JNEUROSCI.3010-16.2017.
Tarfa, R.A., Evans, R.C., Khaliq, Z.M., 2017. Enhanced sensitivity to hyperpolarizing inhibition in mesoaccumbal relative to nigrostriatal dopamine neuron subpopulations. J. Neurosci. 37, 3311-3330. https://doi.org/10.1523/ JNEUROSCI.2969-16.2017.

Tepper, J.M., Damlama, M., Trent, F., 1994. Postnatal changes in the distribution and morphology of rat substantia nigra dopaminergic neurons. Neuroscience 60 , 469-477. https://doi.org/10.1016/0306-4522(94)90258-5.

Tombola, F., Pathak, M.M., Isacoff, E.Y., 2005. Voltage-sensing arginines in a potassium channel permeate and occlude cation-selective pores. Neuron 45, 379-388. https:// doi.org/10.1016/j.neuron.2004.12.047.

Wise, R.A., 2004. Dopamine, learning and motivation. Nat. Rev. Neurosci. 5, 483-494. https://doi.org/10.1038/nrn1406.

Xie, L., Gao, S., Alcaire, S.M., Aoyagi, K., Wang, Y., Griffin, J.K., Stagljar, I., Nagamatsu, S., Zhen, M., 2013. NLF-1 delivers a sodium leak channel to regulate neuronal excitability and modulate rhythmic locomotion. Neuron 77, 1069-1082. https://doi.org/10.1016/j.neuron.2013.01.018.

Yeh, E., Ng, S., Zhang, M., Bouhours, M., Wang, Y., Wang, M., Hung, W., Aoyagi, K., Melnik-Martinez, K., Li, M., Liu, F., Schafer, W.R., Zhen, M., 2008. A putative cation channel, NCA-1, and a novel protein, UNC-80, transmit neuronal activity in C. elegans. PLoS Biol. 6, e55. https://doi.org/10.1371/journal.pbio.0060055. 